\title{
QNREL
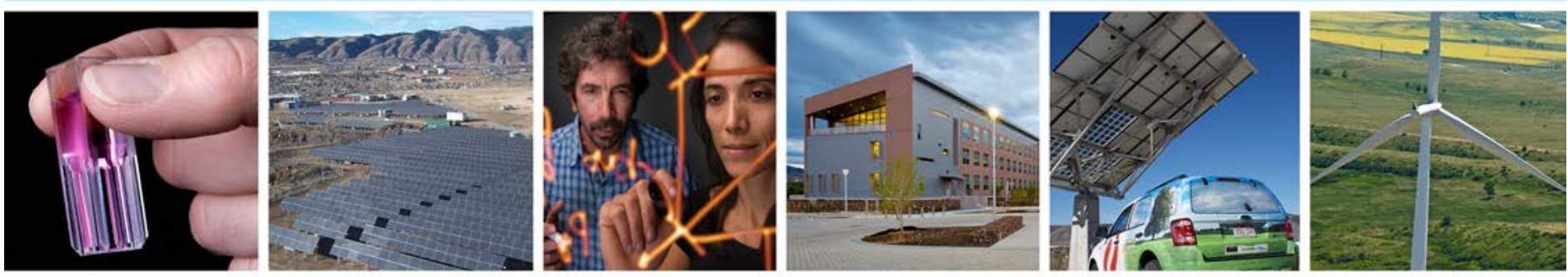

\section{Temporal and Spatial Comparison of Gridded TMY, TDY, and TGY Data Sets}

A. Habte, A. Lopez, M. Sengupta, and S. Wilcox National Renewable Energy Laboratory

NREL is a national laboratory of the U.S. Department of Energy Office of Energy Efficiency \& Renewable Energy Operated by the Alliance for Sustainable Energy, LLC

This report is available at no cost from the National Renewable Energy Laboratory (NREL) at www.nrel.gov/publications.

Technical Report

NREL/TP-5D00-60886

February 2014

Contract No. DE-AC36-08GO28308 


\title{
Temporal and Spatial Comparison of Gridded TMY, TDY, and TGY Data Sets
}

\author{
A. Habte, A. Lopez, M. Sengupta, \\ and S. Wilcox \\ National Renewable Energy Laboratory \\ Prepared under Task No. SS13.3521
}

National Renewable Energy Laboratory 15013 Denver West Parkway Golden, CO 80401

303-275-3000 • www.nrel.gov
NREL is a national laboratory of the U.S. Department of Energy Office of Energy Efficiency \& Renewable Energy Operated by the Alliance for Sustainable Energy, LLC

This report is available at no cost from the National Renewable Energy Laboratory (NREL) at www.nrel.gov/publications.

\section{Technical Report}

NREL/TP-5D00-60886

February 2014

Contract No. DE-AC36-08GO28308 


\title{
NOTICE
}

This report was prepared as an account of work sponsored by an agency of the United States government. Neither the United States government nor any agency thereof, nor any of their employees, makes any warranty, express or implied, or assumes any legal liability or responsibility for the accuracy, completeness, or usefulness of any information, apparatus, product, or process disclosed, or represents that its use would not infringe privately owned rights. Reference herein to any specific commercial product, process, or service by trade name, trademark, manufacturer, or otherwise does not necessarily constitute or imply its endorsement, recommendation, or favoring by the United States government or any agency thereof. The views and opinions of authors expressed herein do not necessarily state or reflect those of the United States government or any agency thereof.

This report is available at no cost from the National Renewable Energy Laboratory (NREL) at www.nrel.gov/publications.

Available electronically at http://www.osti.gov/bridge

Available for a processing fee to U.S. Department of Energy and its contractors, in paper, from:

\author{
U.S. Department of Energy \\ Office of Scientific and Technical Information \\ P.O. Box 62 \\ Oak Ridge, TN 37831-0062 \\ phone: 865.576 .8401 \\ fax: 865.576 .5728 \\ email: mailto:reports@adonis.osti.gov
}

Available for sale to the public, in paper, from:

\author{
U.S. Department of Commerce \\ National Technical Information Service \\ 5285 Port Royal Road \\ Springfield, VA 22161 \\ phone: 800.553 .6847 \\ fax: 703.605.6900 \\ email: orders@ntis.fedworld.gov \\ online ordering: http://www.ntis.gov/help/ordermethods.aspx
}

Cover Photos: (left to right) photo by Pat Corkery, NREL 16416, photo from SunEdison, NREL 17423, photo by Pat Corkery, NREL 16560, photo by Dennis Schroeder, NREL 17613, photo by Dean Armstrong, NREL 17436, photo by Pat Corkery, NREL 17721. 


\section{Acknowledgments}

The continued support and indispensable advice of Daryl Myers (NREL, retired) and Thomas Stoffel (NREL, retired) is greatly acknowledged. We are grateful to Billy Roberts and Rebecca Stubbs for assisting in the production of maps and data processing. We thank Michael Dooraghi for his input and thorough review of the document. 


\section{List of Acronyms}

$\mathrm{CDF}$

$\mathrm{COV}$

DNI

GHI

NSRDB

TDY

TGY

TMY cumulative distribution frequency

coefficient of variation

direct normal irradiance

global horizontal irradiance

National Solar Radiation Database

typical direct (normal irradiance) year

typical global (horizontal irradiance) year

typical meteorological year 


\section{Executive Summary}

Typical Meteorological Year (TMY) data sets provide industry standard resource information for building designers and are commonly used by the solar industry to estimate photovoltaic and concentrating solar power system performance. They are the basis for system performance and economic models such as PVWatts, ${ }^{1}$ System Advisor Model (SAM), ${ }^{2}$ and Solar Prospector. ${ }^{3}$ Historically, TMY data sets were only available for certain station locations, but current TMY data sets are available on the same grid as the National Solar Radiation Database (NSRDB) data and are referred to as the gridded TMY. This gridded TMY data is derived from the $10-\mathrm{km}$ by 10-km gridded NSRDB data (including the years from 1998 to 2009). A gridded TMY file is created by concatenating 12 typical meteorological months from statistically analyzed and selected individual months from the entire set of available years. The selected months (which may be from different years) are then joined to make one serially complete year. A typical meteorological month is generated through cumulative distribution frequency (CDF) analysis in which a typical month is selected closer to the long-term monthly average CDF (Wilcox and Marion 2008). For example, in this case the month of January was selected from the 12 Januarys during the 1998 to 2009 period. The remaining months were selected in similar fashion. Ten indices were used to select a TMY month. These are described in Table 1. The indices are essential for selecting the typical month using a weighting factor for each parameter, which ultimately includes considering the monthly mean and median and the persistence of weather. The series of steps that were carried out to acquire the typical month is described in the Users Manual for TMY3 Data Sets (Wilcox and Marion 2008).

A system performance analysis for photovoltaics and concentrating solar power projects should generally consider high weighting factors for the solar components; as such, some of the meteorological parameters in Table 1 might not be relevant for these applications. For this reason, typical direct (normal irradiance) year (TDY) and typical global (horizontal irradiance) year (TGY) data sets were also produced, whereby the weighting focused on the irradiance components of the data rather than the meteorological data. The weighting factor for each solar component is described in Table 1. The process of generating TDY and TGY data sets is tailored to generating solar component values that are as close as possible to the long-term means for those parameters (as opposed to the "typical" conditions defined by the usual TMY statistical analysis) and are not influenced by other parameters. In this report, a comparison of TMY, TDY, and TGY data sets were performed to better understand the impact of ancillary weather variables upon them.

We analyzed the temporal and spatial variability of the typical year data sets. The spatial variability was calculated using the coefficient of variations of adjacent pixels on a monthly basis for the TDY and TGY data sets and also for the TMY data set. The temporal variability was analyzed by calculating the standard deviation of the monthly and annual gridded data. These analyses identified geographical areas of high and low temporal and spatial variability, thereby providing insight into the representativeness of a particular TMY data set for use in renewable energy as well as other applications.

\footnotetext{
${ }^{1}$ http://www.nrel.gov/rredc/pvwatts/

2 https://sam.nrel.gov/

3 http://maps.nrel.gov/prospector
} 


\section{Table of Contents}

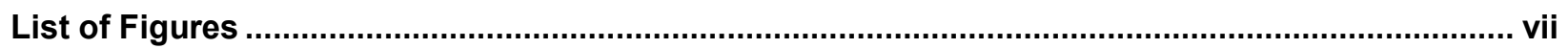

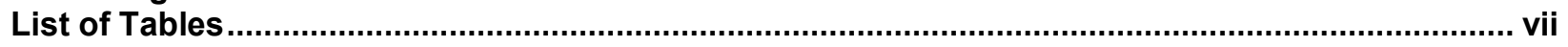

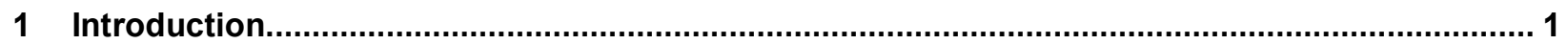

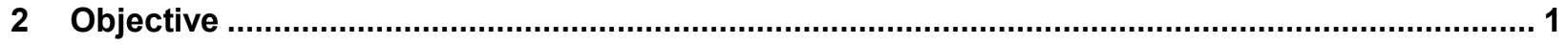

3 Method

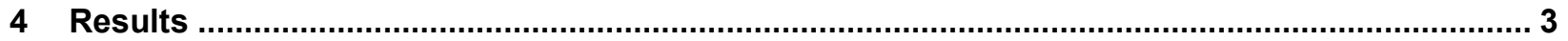

4.1 Comparison of TMY, TDY, and TGY Data Sets ................................................................ 3

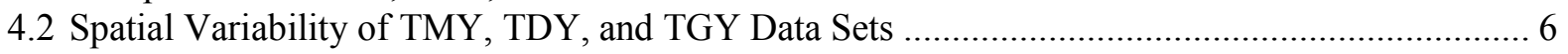

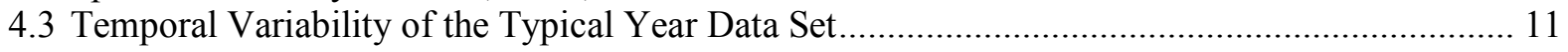

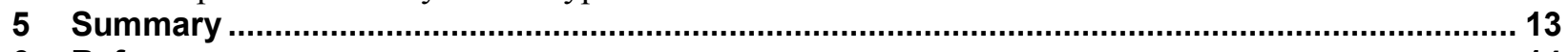

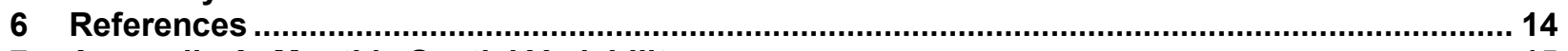

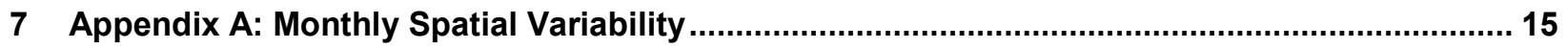

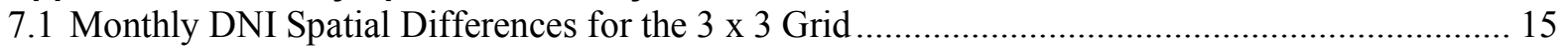

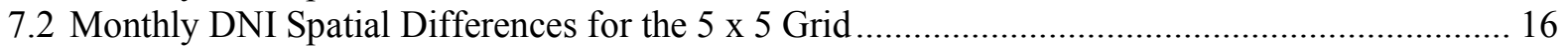

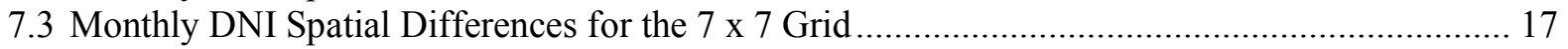

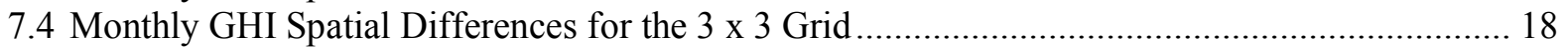

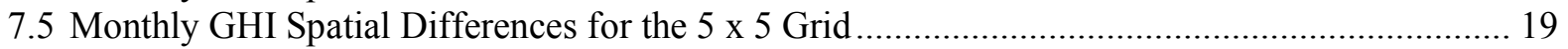

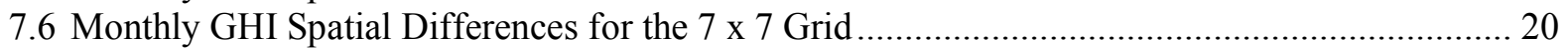

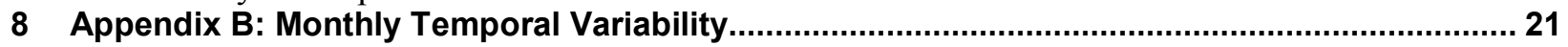

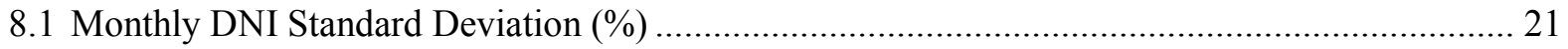

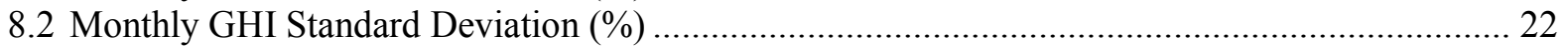




\section{List of Figures}

Figure 1. The distribution of the pixels in each spatial variability analysis. The black center pixels were compared to each of the gray pixels.

Figure 2. The top two figures represent DNI data sets for TMY (DNI) and TDY developed using meteorological and irradiance weighting factors, respectively. The bottom two figures represent GHI for TMY (GHI) and TGY developed using meteorological and irradiance weighting factors, respectively.

Figure 3. (Left) DNI percent comparison (TDY-TMY (DNI)) and (right) GHI percent comparison (TGY-TMY (GHI)). The histogram box represents $95 \%$ of the difference.

Figure 4. Meteorological parameters used in the production of TMY data sets compared to the TDY and TGY meteorological parameters

Figure 5. Understanding spatial variability of neighboring pixels for the $3 \times 3,5 \times 5$, and $7 \times 7$ grid comparisons for the annual TMY, TDY, and TGY data sets (pixels within the United States boundary). Dots are COVs, and the red line represents the mean of the $95 \%$ confidence level, which is the data in the green box.

Figure 6. Map showing spatial variability between neighboring pixels ....................................... 10

Figure 7. Differences among various grid comparisons for the month of January. The arrow demonstrates the increased spatial variability with increased distance between pixels......... 11

Figure 8. Monthly standard deviation distribution in $\mathrm{kWh} / \mathrm{m}^{2} /$ day for the NSRDB gridded DNI and GHI data set.

Figure 9. An illustration of temporal variability for the month of May using the NSRDB data set (1998-2009) for both (a) DNI and (b) GHI

\section{List of Tables}

Table 1. Weighting Parameters for the TMY, TDY, and TGY Data Sets (Modified from Wilcox and Marion 2008)....

Table 2. Average COV for a Typical Data Set Under Different Pixel Distance Comparisons ................ 7

Table 3. Monthly COV for 3 x 3, 5 x 5, and 7 x 7 Grid Comparisons .............................................. 8

Table 4. Average Standard Deviation (Temporal Variability) Obtained From the NSRDB 1998-2009 Data Set. 


\section{Introduction}

Typical meteorological year (TMY) data was first developed by Sandia National Laboratories with the intent of using the data set for solar heating and cooling applications. The development of TMY data at that time produced a consensus data set to be used in computer simulations. The application of TMY data sets has since evolved enormously and has reached the point at which the data sets are more frequently used by applications unrelated to building designers. Currently, the most popular uses are in the solar energy industry, where renewable energy analysts use TMY data sets as inputs into solar energy models that perform site selection of renewable energy technology deployment, system design, system performance, and system operations. However, it is important to understand the limitations of TMY data sets when using them for certain applications beyond their original intent. It should be noted that TMY data is based on historical data and lacks current or recent real-time meteorological or solar information as well as information about climatic variability of a particular area. The data sets do not include the influence of extreme events such as a volcanic eruption or climatic phenomenon that occur at decadal or longer timescales. Therefore, TMY data sets should not be used for analysis that needs weather information for a particular period and/or to perform real-time or operational assessments of system performance of renewable energy technologies.

In addition to the historical TMY, the National Renewable Energy Laboratory (NREL) recently developed gridded typical direct (normal irradiance) year (TDY) and typical global (horizontal) year (TGY) data sets. These two data sets were developed using generally (but not exactly) the same principles guiding TMY data set generation from the NSRDB gridded satellite data. These gridded data sets provide a $10-\mathrm{km}$ by $10-\mathrm{km}$ pixel for each location/grid. The data sets contain hourly values of solar irradiance and some meteorological elements for one year that exemplifies a longer or multiyear period. The two data sets were designed primarily for system performance analysts whose main interests are in the solar components for designing a particular renewable energy technology or project. These data sets provide another set of inputs for specific users; including other parameters that are traditionally used to generate TMY data in the abovementioned analyses could decrease the effectiveness of such analysis. It should be noted that the only difference between the TMY and newly developed TDY and TGY data sets is the weighting factor used for generating the data sets. For the TDY and TGY data sets, the weighting factors are only the solar parameters, whereas TMY includes non-zero weighting factors for both the solar and meteorological components. The TDY data set is developed using $100 \%$ weighting for direct normal irradiance (DNI), whereas the TGY data set uses 100\% weighting for global horizontal irradiance (GHI). This indicates that the other meteorological indices were set to zero in both TDY and TGY cases. Therefore, users of these data sets should clearly understand the differences between these two types of data sets when applying them to a specific project.

\section{Objective}

Three essential assessments were conducted in this report: (1) understanding the difference between TMY versus TDY and TMY versus TGY; (2) assessing the spatial variability among neighboring pixels of the gridded TMY, TDY, and TGY data; and (3) understanding the temporal variability of these data sets. 


\section{Method}

The gridded TMY, TDY, and TGY data sets were created using the 12-year (from 1998 to 2009) NSRDB gridded satellite data. These gridded data sets represent data for the center within a10$\mathrm{km}$ by $10-\mathrm{km}$ area for each location/grid. Each data set contains hourly average values of solar irradiance and some meteorological elements during a period of one year that represent a longer or multiyear period. As discussed in the background section, typical year data sets for the TMY, TDY, and TGY were developed using the weighting factors listed in Table 1. The meteorological data sets used to create the TMY were derived from the North American Regional Reanalysis data sets from the National Oceanic and Atmospheric Administration (NARR; Mesinger et al. 2006).

A comparison of TMY (DNI) versus TDY, and TMY (GHI) versus TGY was performed using simple subtraction of the typical yearly average data among the data sets. The percentage difference was obtained by dividing the difference of DNI and GHI by the TMY (DNI) and TMY (GHI) for the respective periods.

Table 1. Weighting Parameters for the TMY, TDY, and TGY Data Sets (Modified from Wilcox and Marion 2008)

\begin{tabular}{cccc}
\hline Index & TMY & TDY & TGY \\
\hline Max Dry Bulb Temp & $1 / 20$ & 0 & 0 \\
\hline Min Dry Bulb Temp & $1 / 20$ & 0 & 0 \\
\hline Mean Dry Bulb Temp & $2 / 20$ & 0 & 0 \\
\hline Max Dew Point Temp & $1 / 20$ & 0 & 0 \\
\hline Min Dew Point Temp & $1 / 20$ & 0 & 0 \\
\hline Mean Dew Point Temp & $2 / 20$ & 0 & 0 \\
\hline Max Wind Velocity & $1 / 20$ & 0 & 0 \\
\hline Mean Wind Velocity & $1 / 20$ & 0 & 0 \\
\hline GHI & $5 / 20$ & 0 & $20 / 20$ \\
\hline DNI & $5 / 20$ & $20 / 20$ & 0 \\
\hline
\end{tabular}

The spatial variability analysis was implemented by comparing a center pixel with neighboring pixels (Figure 1). A coefficient of variation (COV) value was generated for each configuration shown in Figure 1.

1. $3 \times 3$ pixels: Each pixel represents a $10-\mathrm{km}$ by $10-\mathrm{km}$ area. In this comparison, the total area covered by the pixels was $30 \mathrm{~km}$ by $30 \mathrm{~km}$. The center pixel was compared to the adjacent 8 pixels.

2. 5 x 5 pixels: The center pixel was compared to the farthest surrounding pixels in all directions.

3. 7 x 7 pixels: The center pixel was compared to the 24 farthest surrounding pixels. 


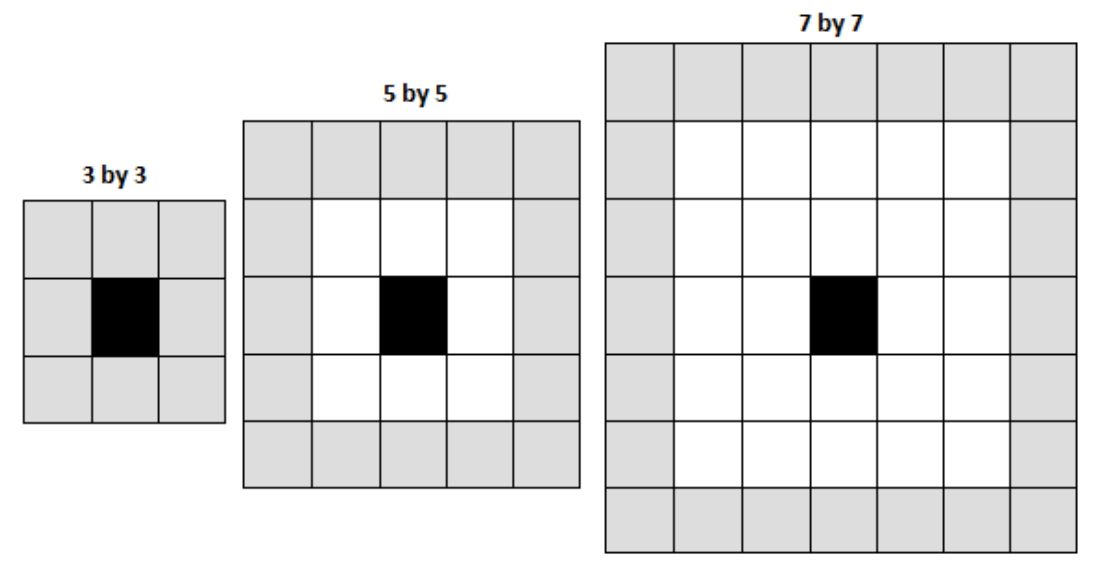

Figure 1. The distribution of the pixels in each spatial variability analysis. The black center pixels were compared to each of the gray pixels.

COV was calculated using the following equation:

$$
\operatorname{COV}\left(T x Y_{a}, T x Y_{b}\right)=\frac{\left(\sqrt{\frac{\sum_{i=1}^{i=n}\left(\overline{T x Y_{b_{i}}}-\overline{T x Y_{a}}\right)^{2}}{n}}\right)}{\overline{T x Y_{a}}}
$$

Where, $\overline{T x Y_{a}}$ represent the average irradiance of the TMY, TDY, or TGY data set for a specified averaging time (monthly or yearly) of the center pixel, $\overline{T x Y_{b}}$ represents the average of the neighboring (or comparison) pixel of the TMY, TDY, or TGY irradiance data values, and $n$ represents the number of surrounding pixels in the comparison.

The temporal variability was assessed using a standard deviation calculation of the monthly gridded NSRDB data.

$$
\text { stdev }=\sqrt{\frac{\sum_{i=1}^{n}\left(X_{i}-\bar{X}\right)^{2}}{n-1}}
$$

Where $X$ represents the monthly mean data of the gridded NSRDB for an individual year and $\bar{X}$ represents the average of the 12 months during the 1998 to 2009 data set, e.g., the average of 12 Januarys during the 1998 to 2009 data set.

\section{Results}

The purpose of the analysis was to determine the differences among the TMY, TDY, and TGY data sets and understand the temporal and spatial variability of the TMY, TDY, and TGY data sets.

\subsection{Comparison of TMY, TDY, and TGY Data Sets}

The weights shown in Table 1 indicate that GHI and DNI had much higher weighting than the other atmospheric variables in the TMY calculations. 
However, Figure 2 demonstrates that the differences among the TMY (DNI) and TDY, and TMY (GHI) and TGY were indeed small, and the figures appeared to be visually quite similar, even the contour lines where very small differences would be conspicuous. This verifies that the solar radiation inputs indeed dominated the other meteorological variables because of the high weighting assigned to those inputs. It also indicates that the 12-year period of the TDY and TGY data sets may be representative of the TMY data sets within the $500 \mathrm{~W} / \mathrm{m}^{2} /$ day $\left(0.5 \mathrm{~kW} / \mathrm{m}^{2} /\right.$ day $)$ resolution of the contour intervals shown in Figure 2.

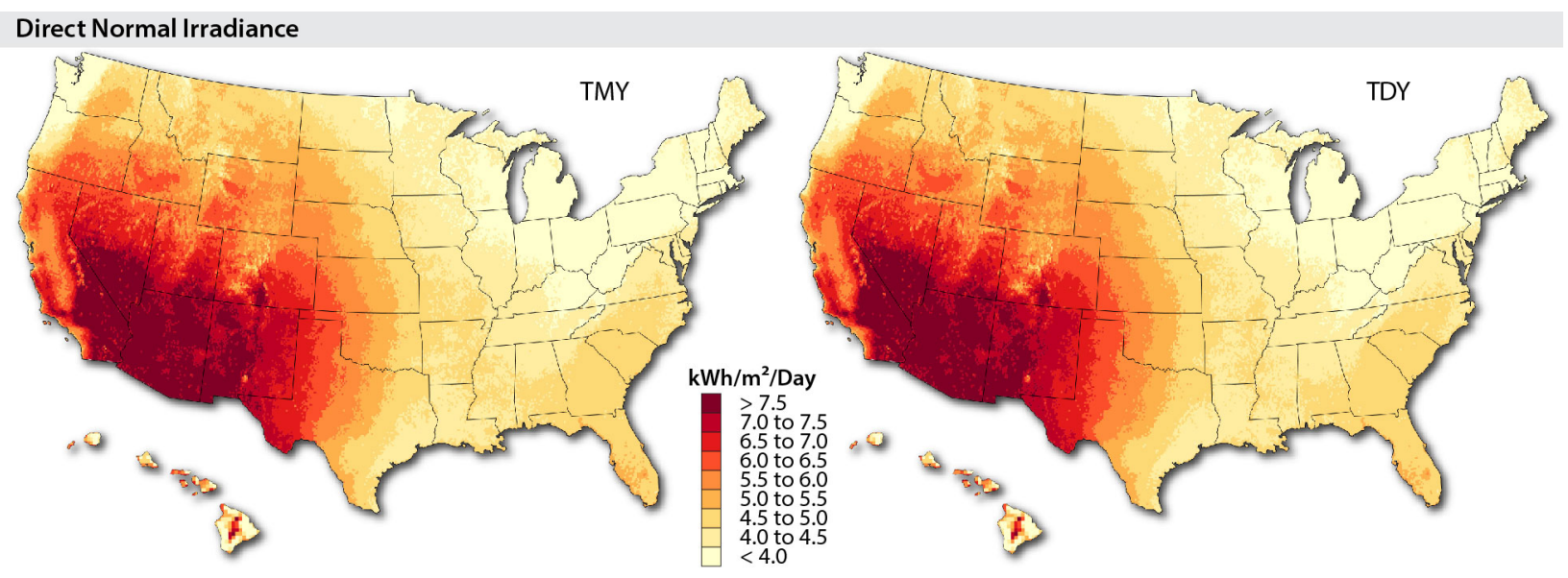

Global Horizontal Irradiance

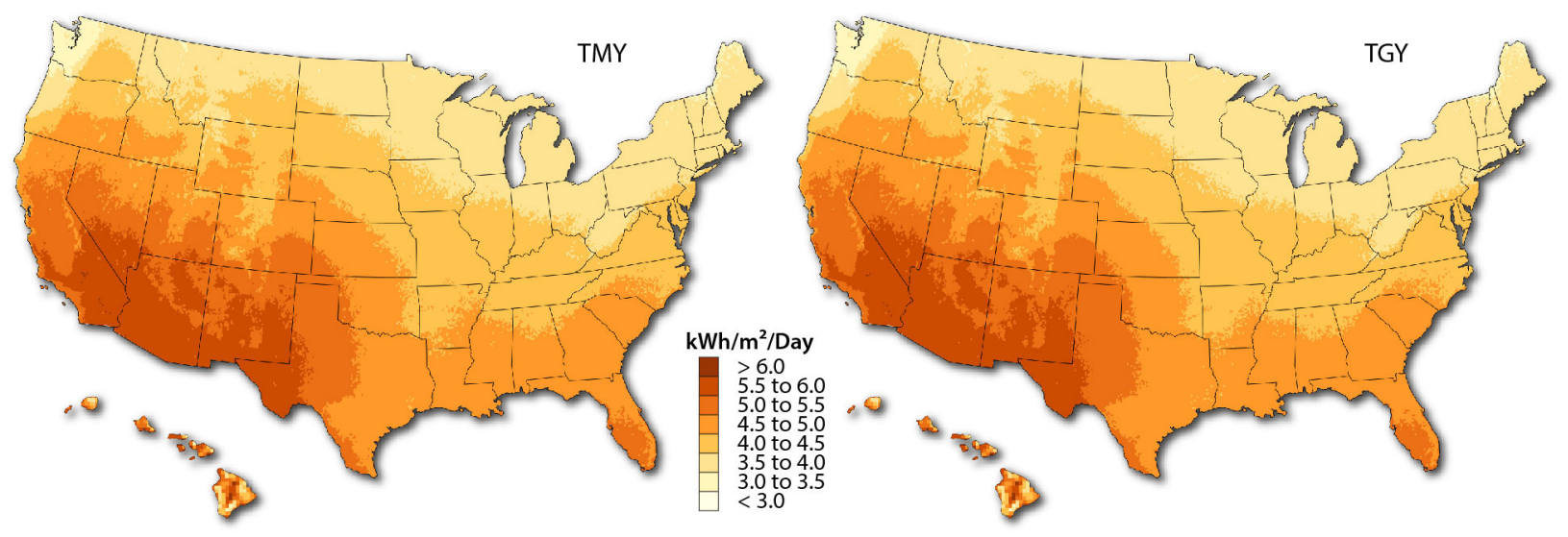

Figure 2. The top two figures represent DNI data sets for TMY (DNI) and TDY developed using meteorological and irradiance weighting factors, respectively. The bottom two figures represent GHI for TMY (GHI) and TGY developed using meteorological and irradiance weighting factors, respectively.

Figure 3 shows the differences among the TMY and TGY or TDY in percent for a typical year. The histograms in the same figure show the result of the percent difference obtained using a 95 percentile criteria (light green box). Ninety-five percent of the time, most locations demonstrated less than 1\% difference between TMY (DNI) and TDY. The TMY (GHI) and TGY data sets appeared to have relatively small differences that were below $0.5 \%$ difference for nearly $95 \%$ of the time. Further, the speckled appearance of the difference plots (Figure 3) indicates a somewhat random distribution of higher magnitude differences, whereas one might expect smoother transitions as a function of climate or geography (and such artifacts are even visible in 
the plots as patterns in the speckles). This could possibly be attributed to the inevitable choosing by the algorithm of different month-years for the different data sets. While the algorithm attempts to force uniformity based on long term means, minor differences among years is not surprising. However, even the greatest differences among nearby pixels is still less than $1.5 \%$, indicating acceptable uniformity for many applications.
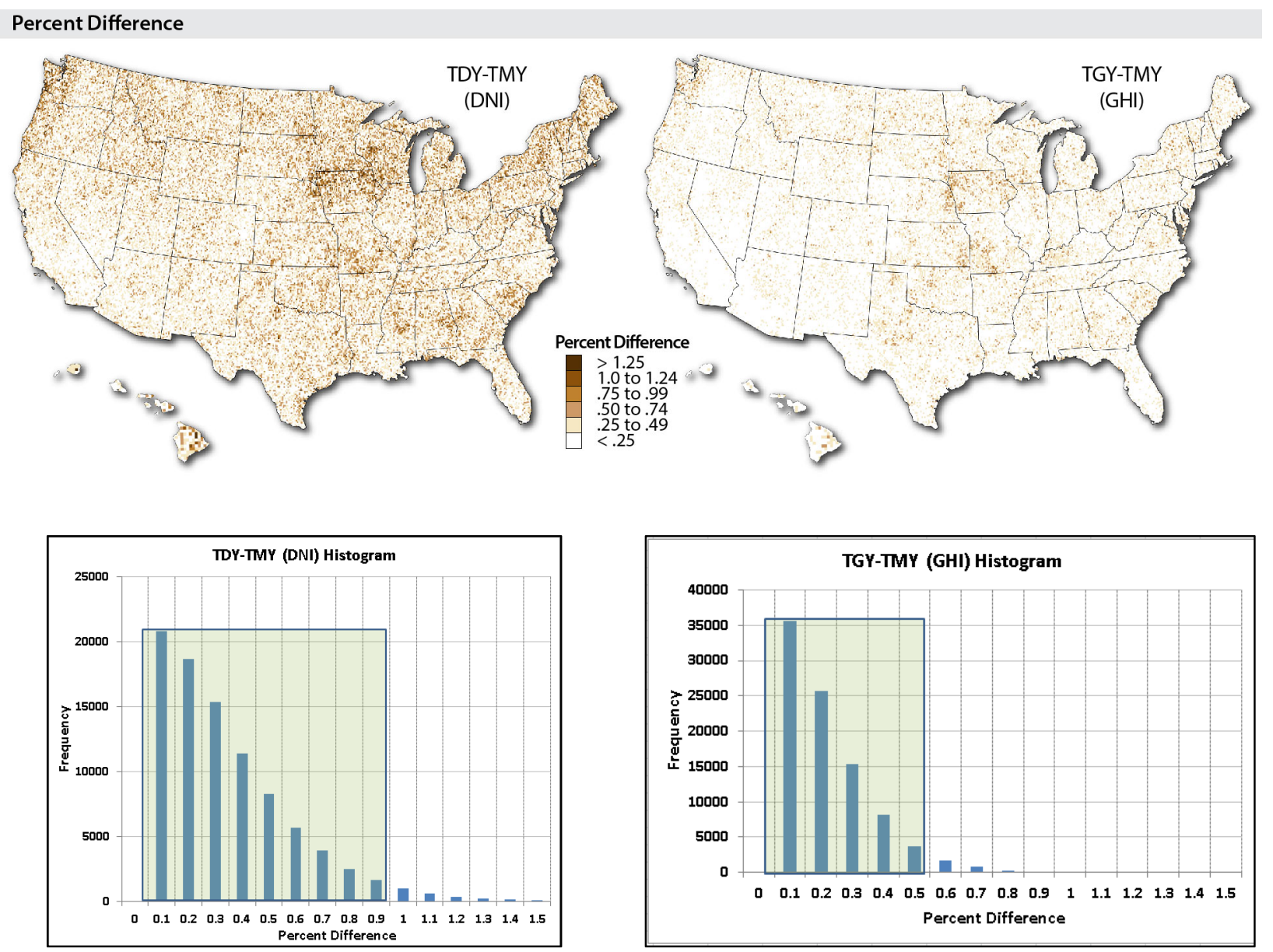

Figure 3. (Left) DNI percent comparison (TDY-TMY (DNI)) and (right) GHI percent comparison (TGY-TMY (GHI)). The histogram box represents $95 \%$ of the difference.

Figure 4 demonstrates the spatial variability of the meteorological parameters that were used as weighting factors for the TMY data. The figure does not show clear separation among the TMY, TDY, and TGY meteorological parameters. This again affirms that the solar flux held more weight in generating these data sets (Sawaqed et al. 2005). 

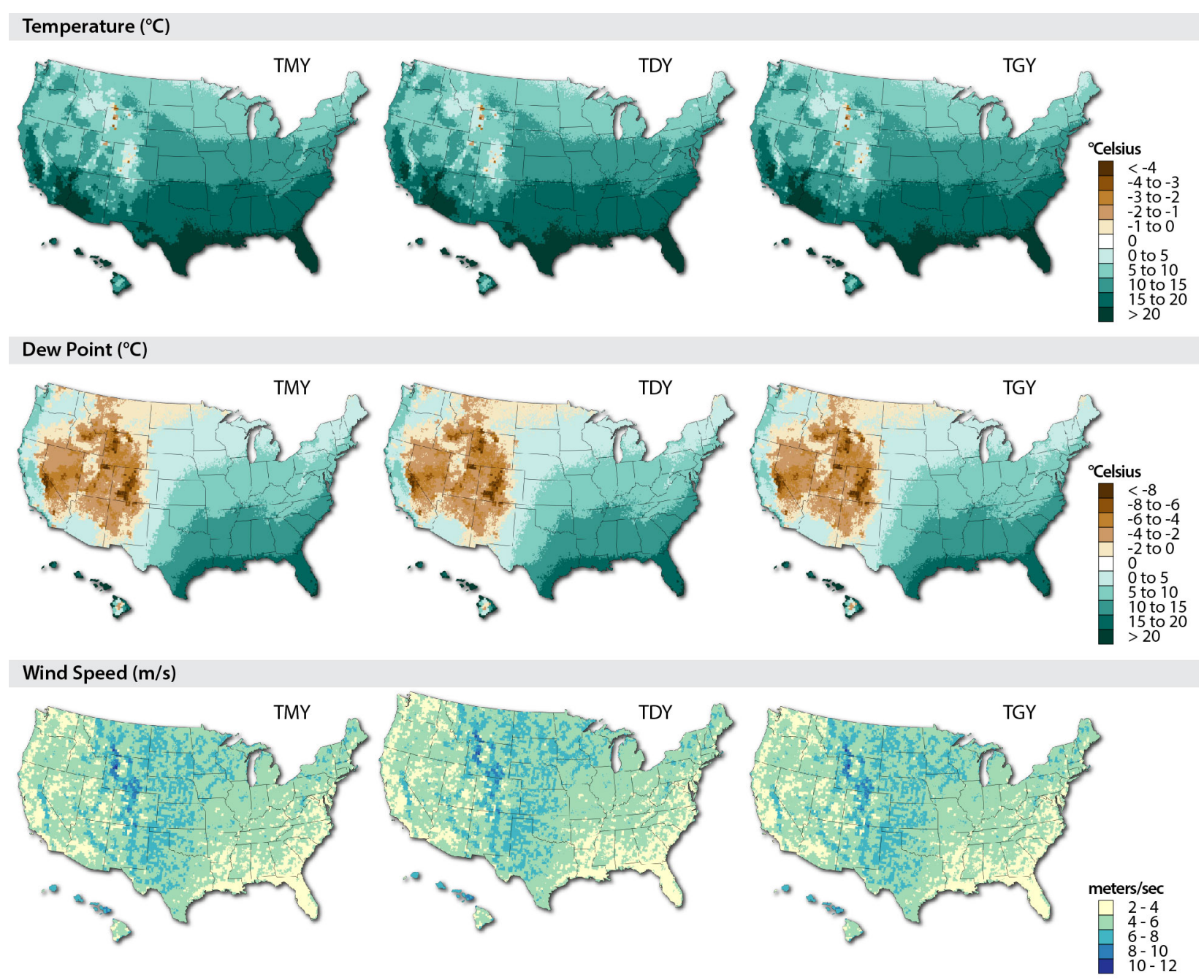

Figure 4. Meteorological parameters used in the production of TMY data sets compared to the TDY and TGY meteorological parameters

However, solar irradiance differences can be quite large when comparing monthly TMY (DNI) and TDY data sets, or monthly TMY (GHI) and TGY data sets, especially when a selected typical month for each typical year data set is obtained from a different year because of the differences in the weighting. These differences are presented in more detail in Section 4.2 and Section 4.3 on spatial and temporal variability, respectively.

Overall, it appears that the annual differences among the data sets used to represent DNI and GHI during a typical year were minimal, with no discernible trend.

\subsection{Spatial Variability of TMY, TDY, and TGY Data Sets}

In this section, we tried to identify the spatial variability of the different typical year data sets. For those interested in the analysis of system performance, the results would assist them in better understanding the available resources and where to deploy specific types of energy systems. Further, the value of the spatial data is to understand the spatial limits of a measurement value. In areas with low variability, one may have confidence in the resource information over wide geographic area, whereas in a high variability area, more careful analysis may be required when 
considering closely spaced locations. However, information derived from the analysis using the TMY, TDY, or TGY data sets should be accompanied by other solar resource information, such as ground-measured or satellite-modeled data sets, because the TMY data lacks real-time and climatic information.

As presented in Figure 5, Figure 6, and Table 2, the spatial variability was analyzed using a COV method. The results demonstrated that adjacent pixels have a lower COV, and as the distance increases between the center pixel (target) and the farthest pixel the difference increases.

Table 2. Average COV for a Typical Data Set Under Different Pixel Distance Comparisons

\begin{tabular}{|ccccc|} 
& \multicolumn{4}{c}{ COV } \\
& TMY (DNI) & TDY & TMY (GHI) & TGY \\
\hline $\mathbf{3} \times \mathbf{3}$ & 0.01983 & 0.01884 & 0.00981 & 0.00917 \\
\hline $\mathbf{5} \times \mathbf{5}$ & 0.02524 & 0.02416 & 0.01276 & 0.0121 \\
\hline $\mathbf{7} \times \mathbf{7}$ & 0.02956 & 0.0285 & 0.01525 & 0.01461 \\
\hline
\end{tabular}

This physically implies that the lower the variance between adjacent pixels, the higher the likelihood that the center pixel is similar to its neighbor pixel. As expected, the $3 \times 3$ grid shown in Figure 6 for the DNI and GHI data sets demonstrated less spatial variability. Table 3 and Appendix A: Monthly Spatial Variability demonstrate the monthly spatial differences for various grid comparisons. The winter months had higher spatial differences than the summer months. This was true for all grid comparisons. 
Table 3. Monthly COV for 3 × 3, 5 × 5, and 7 × 7 Grid Comparisons

\begin{tabular}{|c|c|c|c|c|}
\hline \multicolumn{5}{|c|}{ COV } \\
\hline Month & TMY (DNI) & TDY & TMY (GHI) & TGY \\
\hline \multicolumn{5}{|c|}{$3 \times 3$} \\
\hline January & 0.078 & 0.070 & 0.039 & 0.036 \\
\hline February & 0.073 & 0.068 & 0.037 & 0.035 \\
\hline March & 0.056 & 0.051 & 0.029 & 0.027 \\
\hline April & 0.042 & 0.038 & 0.023 & 0.020 \\
\hline May & 0.041 & 0.037 & 0.021 & 0.019 \\
\hline June & 0.037 & 0.034 & 0.019 & 0.017 \\
\hline July & 0.033 & 0.031 & 0.017 & 0.016 \\
\hline August & 0.036 & 0.033 & 0.019 & 0.017 \\
\hline September & 0.034 & 0.032 & 0.019 & 0.017 \\
\hline October & 0.039 & 0.038 & 0.022 & 0.020 \\
\hline November & 0.052 & 0.049 & 0.027 & 0.025 \\
\hline December & 0.072 & 0.066 & 0.036 & 0.033 \\
\hline \multicolumn{5}{|c|}{$5 \times 5$} \\
\hline January & 0.092 & 0.083 & 0.046 & 0.043 \\
\hline February & 0.085 & 0.079 & 0.044 & 0.041 \\
\hline March & 0.065 & 0.060 & 0.035 & 0.032 \\
\hline April & 0.049 & 0.045 & 0.027 & 0.024 \\
\hline May & 0.049 & 0.044 & 0.025 & 0.022 \\
\hline June & 0.044 & 0.041 & 0.023 & 0.021 \\
\hline July & 0.040 & 0.038 & 0.021 & 0.019 \\
\hline August & 0.043 & 0.040 & 0.023 & 0.020 \\
\hline September & 0.041 & 0.038 & 0.023 & 0.020 \\
\hline October & 0.047 & 0.045 & 0.027 & 0.024 \\
\hline November & 0.062 & 0.058 & 0.033 & 0.031 \\
\hline December & 0.085 & 0.078 & 0.043 & 0.040 \\
\hline \multicolumn{5}{|c|}{$7 \times 7$} \\
\hline January & 0.101 & 0.092 & 0.052 & 0.048 \\
\hline February & 0.093 & 0.087 & 0.048 & 0.045 \\
\hline March & 0.072 & 0.066 & 0.038 & 0.035 \\
\hline April & 0.054 & 0.049 & 0.029 & 0.027 \\
\hline May & 0.054 & 0.049 & 0.028 & 0.025 \\
\hline June & 0.050 & 0.047 & 0.025 & 0.023 \\
\hline July & 0.046 & 0.043 & 0.024 & 0.022 \\
\hline August & 0.049 & 0.045 & 0.026 & 0.023 \\
\hline September & 0.046 & 0.042 & 0.026 & 0.023 \\
\hline October & 0.052 & 0.050 & 0.030 & 0.028 \\
\hline November & 0.069 & 0.064 & 0.037 & 0.035 \\
\hline December & 0.094 & 0.087 & 0.049 & 0.045 \\
\hline
\end{tabular}


Further, the degree of spatial difference was relatively higher in DNI compared to GHI (Figure 5, Figure 6, and Table 3). The DNI COV for both the TMY (DNI) and TDY data sets showed higher spatial variations, ranging from $0.03 \%$ during summer to $0.08 \%$ during winter; however, the GHI spatial variation in the TMY (GHI) and TGY data sets ranged from $0.02 \%$ during summer to $0.04 \%$ during winter.

In general, the spatial information of the pixels would assist energy analysts in selecting a useful pixel resolution of solar resource data for specific applications (Gueymard et al. 2011).
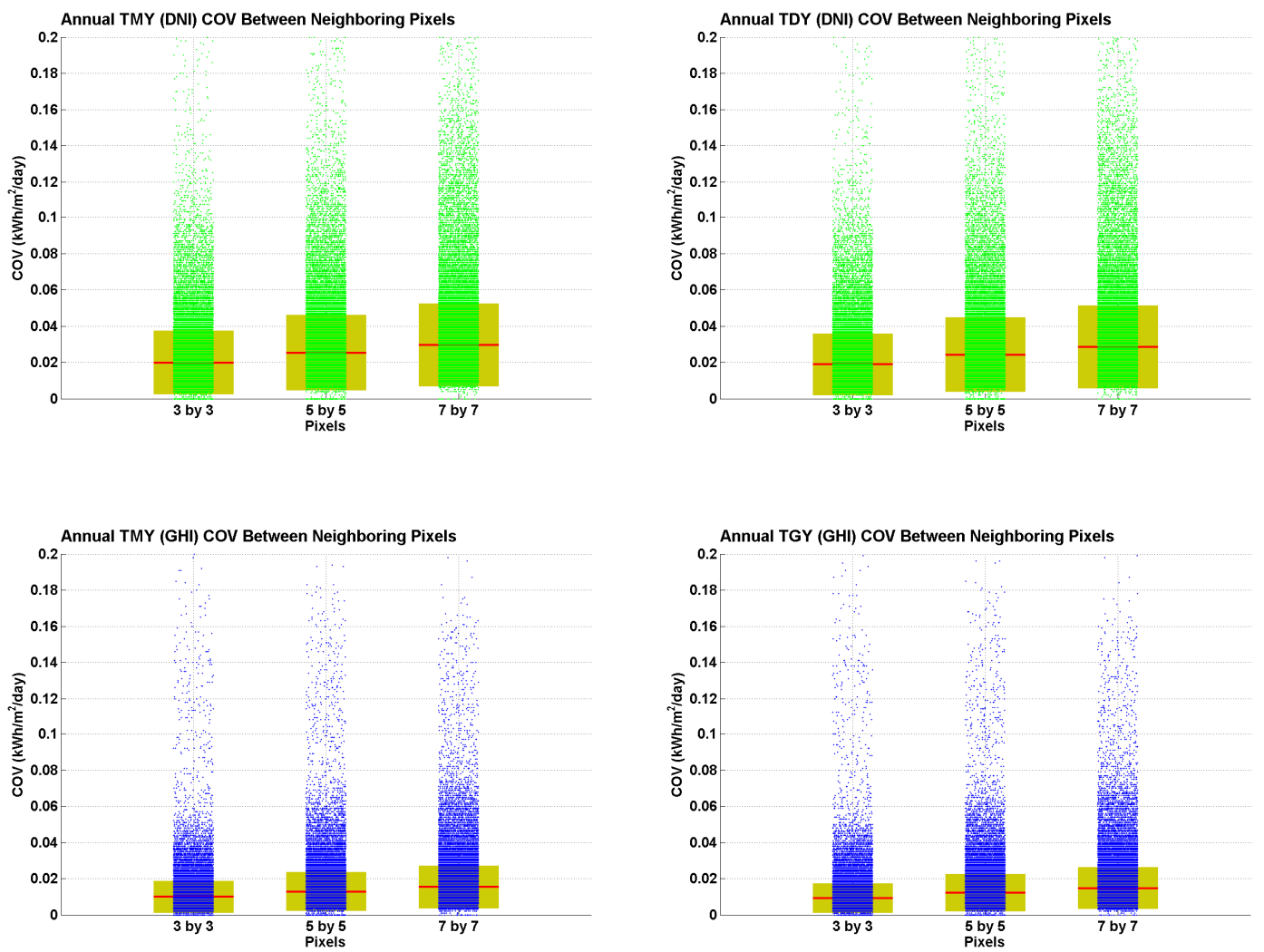

Figure 5. Understanding spatial variability of neighboring pixels for the $3 \times 3,5 \times 5$, and $7 \times 7$ grid comparisons for the annual TMY, TDY, and TGY data sets (pixels within the United States boundary). Dots are COVs, and the red line represents the mean of the $95 \%$ confidence level, which is the data in the green box. 


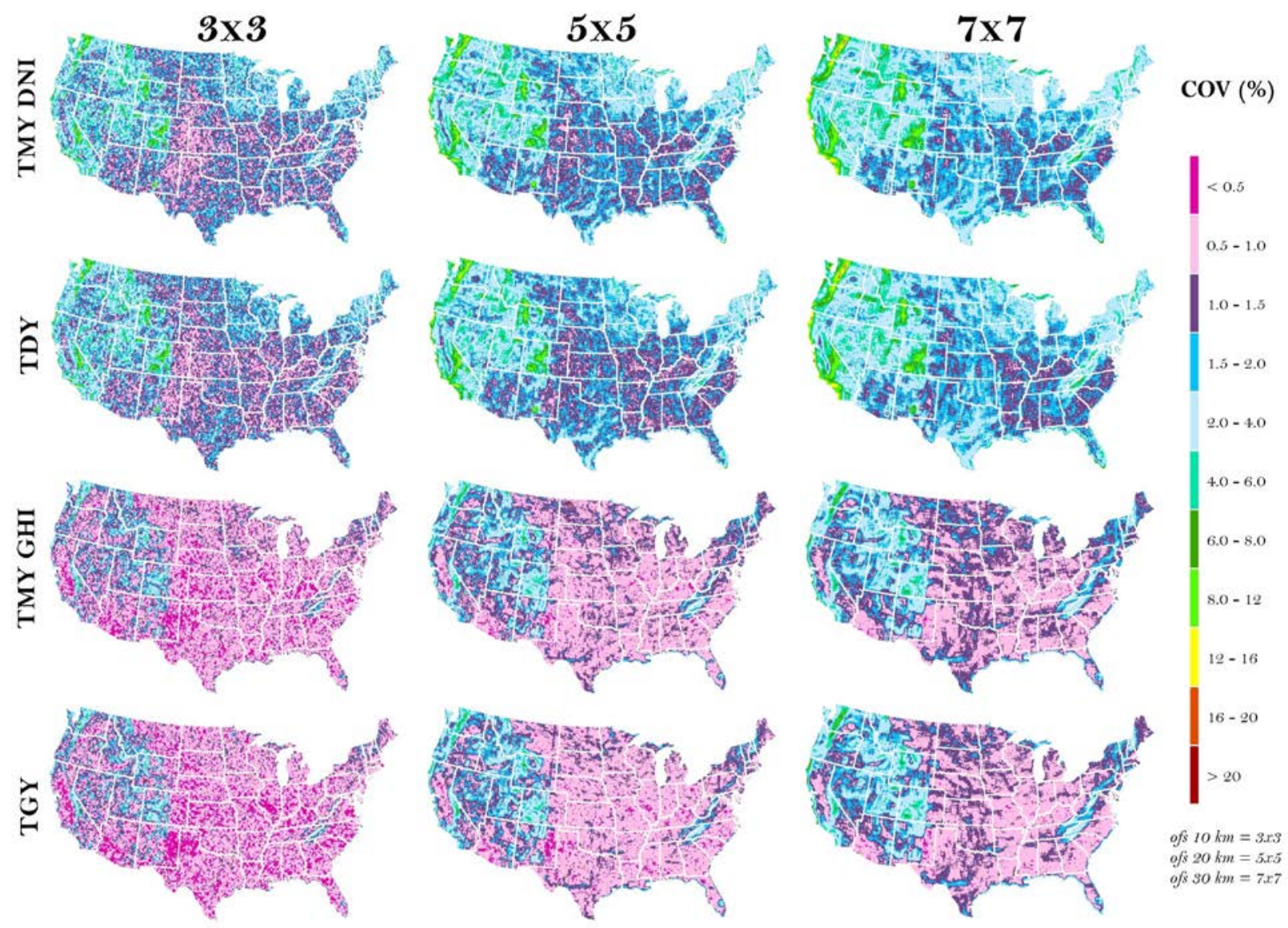

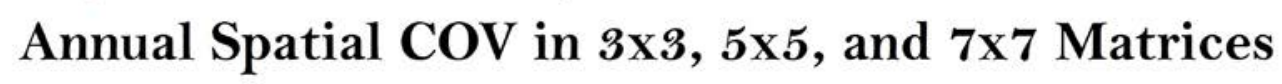

Figure 6. Map showing spatial variability between neighboring pixels

The higher variation in the DNI than the GHI was attributed to the opacity of sky and also aerosols (Gueymard et al. 2011). The magnitude of variation (COV) in the DNI increased rapidly as the compared distance between the center pixel and the farthest pixel increased (Figure 6). The variation of DNI with adjacent pixels could provide system performance analysts with essential information on how the system energy output will be spatially variable in certain locations.

The above inferences about adjacent pixels containing relatively less variance also hold true for the monthly data sets. For instance, Figure 7 shows DNI data for the month of January for the $3 \mathrm{x}$ $3,5 \times 5$, and $7 \times 7$ grid comparisons. As shown in the figure, it is evident that there was less variance in the $3 \times 3$ matrix than in the $5 \times 5$ and $7 \times 7$ comparisons.

Additionally, Figure 7 shows that the spatial differences between the TMY (DNI) and TDY data sets are very similar for each grid comparison. 


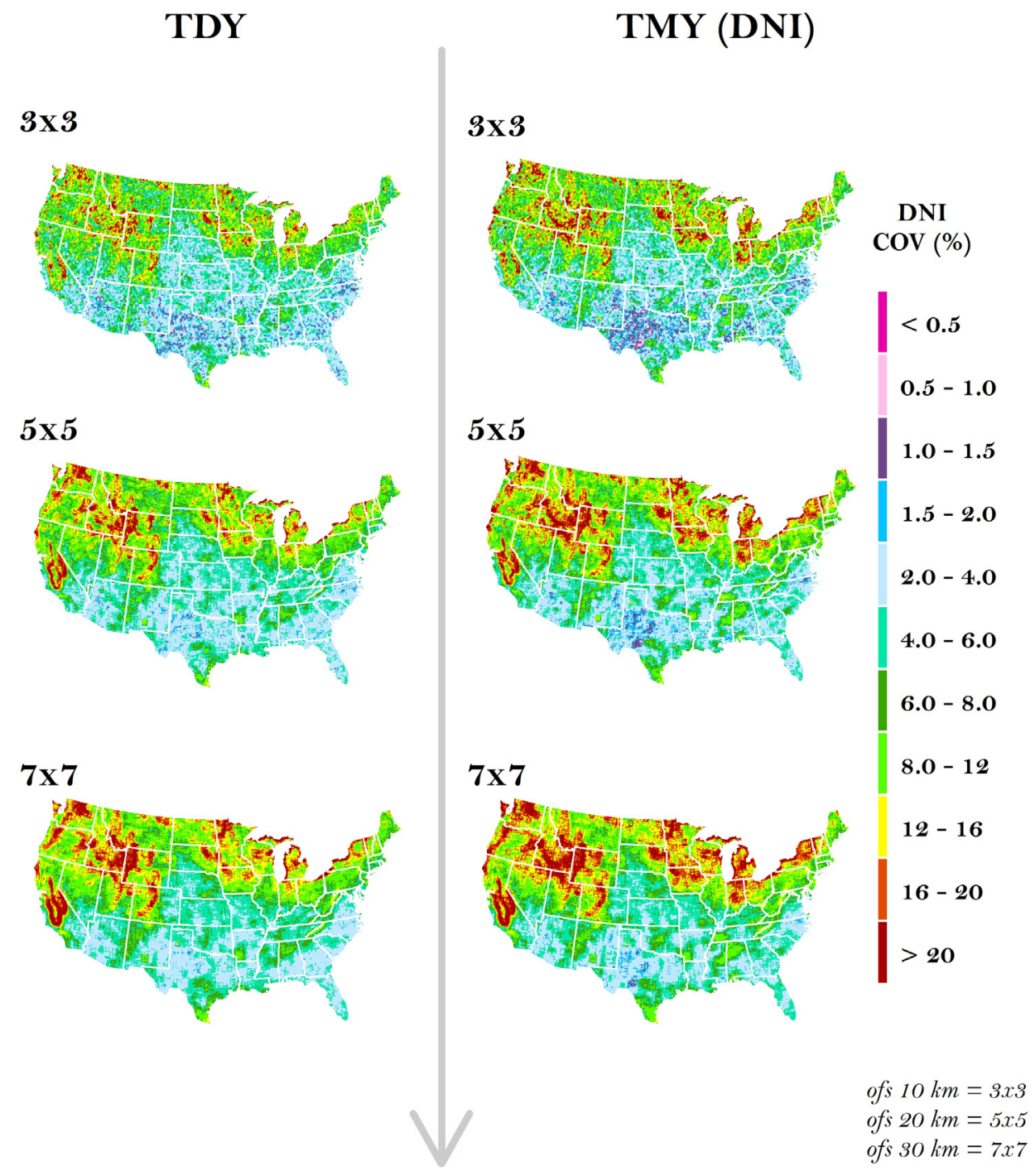

\section{Spatial COV in 3x3, 5x5, and $7 \times 7$ Grids for the Month of January}

Figure 7. Differences among various grid comparisons for the month of January. The arrow demonstrates the increased spatial variability with increased distance between pixels.

\subsection{Temporal Variability of the Typical Year Data Set}

The TMY, TDY, and TGY data sets have natural diurnal and seasonal variations and represent a year of typical climatic conditions of a location (Wilcox and Marion 2008). However, the data sets do not include extreme climatic events such as wildfire or volcanic eruptions. Therefore, care should be taken when using a typical year data set.

In this section, a standard deviation for the monthly gridded NSRDB (1998-2009) data was calculated. The purpose of this analysis was to understand the effectiveness of the TMY data in representing the long-term variations. Table 4 demonstrates the average standard deviation for 
each month from the entire 12-year data set. As shown in the table, the months of February and May had higher standard deviations for DNI and GHI, respectively.

Table 4. Average Standard Deviation (Temporal Variability) Obtained From the NSRDB 1998-2009 Data Set

\begin{tabular}{|ccc|} 
Month & $\begin{array}{c}\text { Average Std. Deviation } \\
\text { (DNI) }\end{array}$ & $\begin{array}{c}\text { Average Std. Deviation } \\
\text { (GHI) }\end{array}$ \\
\hline January & 0.623 & 0.206 \\
\hline February & $\mathbf{0 . 8 2 8}$ & 0.328 \\
\hline March & 0.729 & 0.349 \\
\hline April & 0.676 & 0.364 \\
\hline May & $\mathbf{0 . 7 5 2}$ & $\mathbf{0 . 4 3 4}$ \\
\hline June & 0.748 & 0.415 \\
\hline July & 0.592 & 0.324 \\
\hline August & 0.561 & 0.301 \\
\hline September & 0.597 & 0.299 \\
\hline October & 0.733 & 0.321 \\
\hline November & 0.635 & 0.23 \\
\hline December & 0.606 & 0.187 \\
\hline
\end{tabular}

Figure 8 shows the standard deviation distribution of the GHI and DNI data set for all pixels in the United States. The yellow box illustrates $95 \%$ confidence interval coverage, and the red line is the mean point for the $95 \%$ confidence interval data.
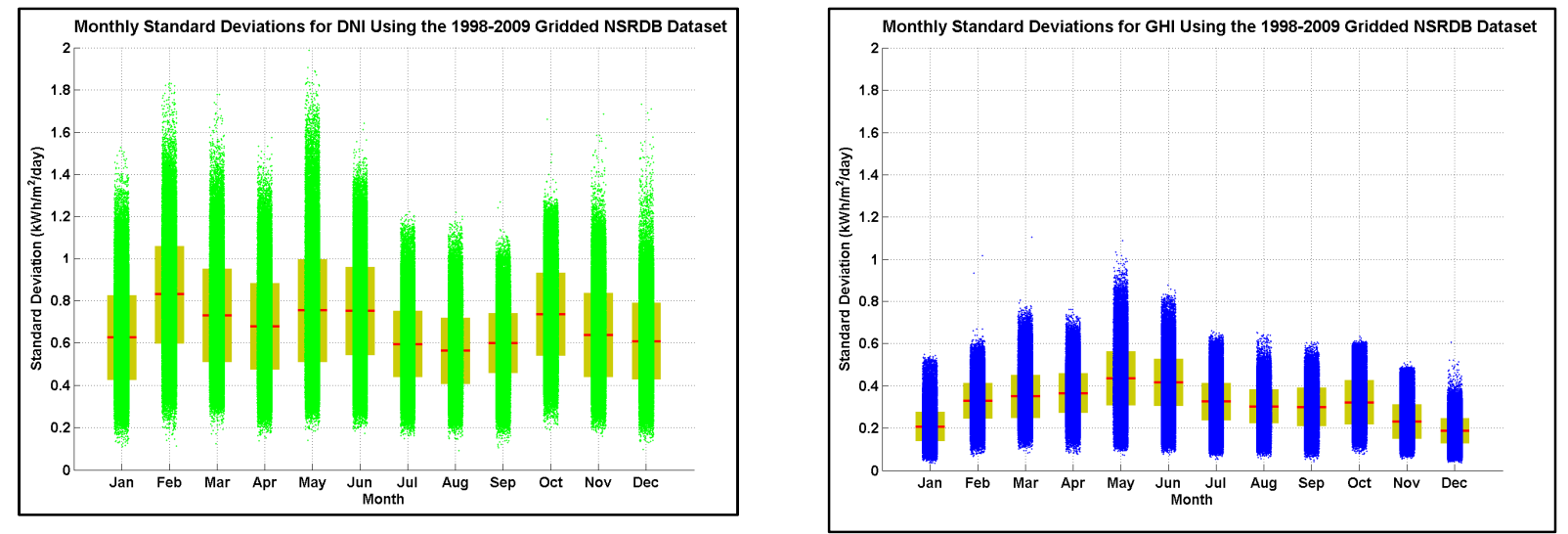

Figure 8. Monthly standard deviation distribution in $\mathrm{kWh} / \mathrm{m}^{2} /$ day for the NSRDB gridded DNI and GHI data set

The hypothesis was that the temporal variations that are apparent in Figure 8 would be captured by the TMY data set. This was true in the absence of extreme weather condition such as volcanic eruption or extensive wildfire. As shown in Figure 9, it is obvious that some months had higher standard deviations than others. Particularly, the month of May had high standard deviation in both the DNI and GHI data sets; therefore, the typical year data set would have some limitations in representing the month of May. 


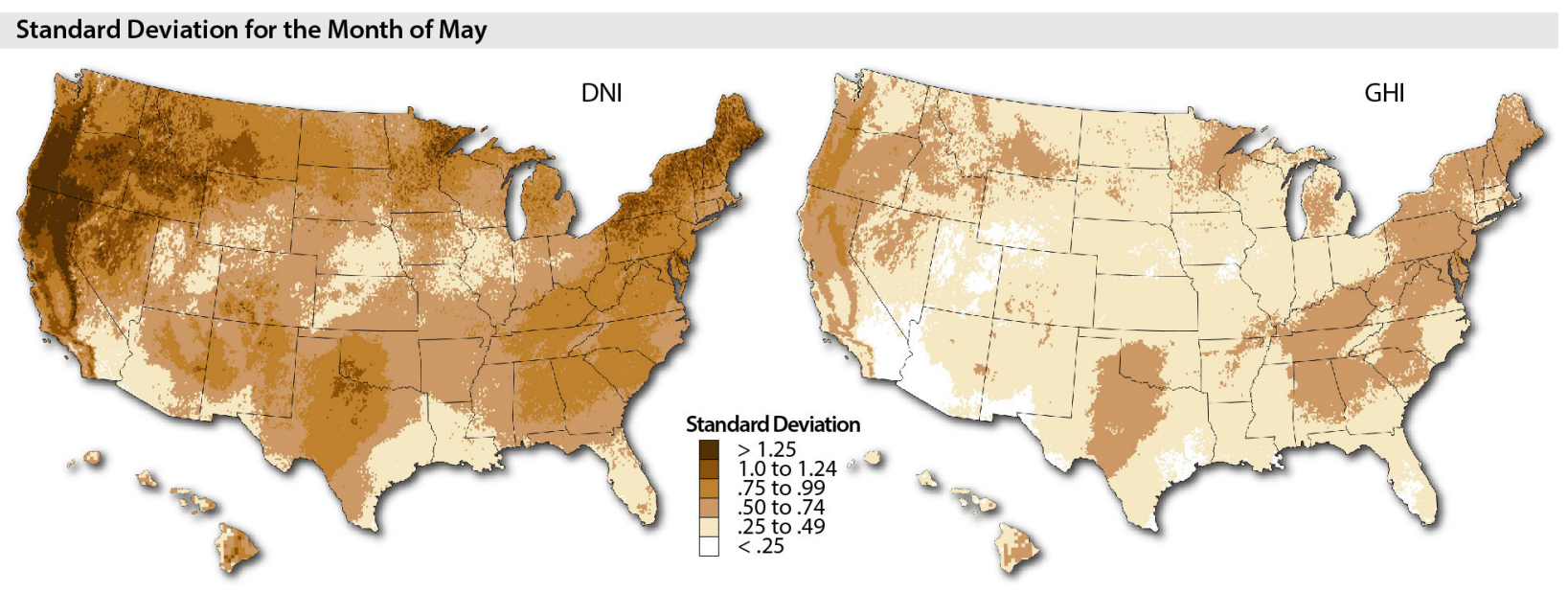

Figure 9. An illustration of temporal variability for the month of May using the NSRDB data set (1998-2009) for both (a) DNI and (b) GHI

As illustrated above, the standard deviations of the irradiance for each month provide useful information on the temporal variability of a typical data set. As mentioned in previous sections, the typical year data set is generated through CDF analysis in which a typical month is selected with the monthly CDF closer to the long-term monthly average CDF. This means that the TMY generated for the month of May (Figure 9) (especially some pixels located in the western states such as California and Oregon) will have higher temporal variability. The selected month of May using the CDF will have relatively less representation of a typical month compared to other selected months. The annual temporal variations included in the typical data set do not depict the monthly variations; therefore, the user of the TMY data set must assess the importance of shorter term (monthly) versus long-term (annual) temporal variability when applying the data to a specific system performance project. Examples include the importance of heating and airconditioning loads (or the lack of the same) in the expected service area.

\section{Summary}

The results of the analysis depicted in this report show that the spatial and temporal variability have similar structure under the TMY (DNI) and TDY data set and also under the TMY (GHI) and TGY data set selection criteria. This is because the solar flux component is apparently the dominant weighting factor in the production of these data sets. However, a month-to-month comparison among typical data sets might have some differences because the sequence of month selection from each year in a typical data set could be different. For instance, the TMY (DNI) for the month of January could come from 1999, but the TDY could be from 2001.

Overall, the inter-annual temporal and spatial variability were captured well among these data sets. Very few months demonstrated relatively higher temporal variability (standard deviation) than others. For these months, a typical data set would lack a full representation of the monthly variations when developing a typical year data set. In future productions of TMY data sets, it is recommend that a standard deviation could be used as one of the weighting factors, or as a source of additional uncertainty in the development of a typical year data set. 


\section{References}

Gueymard, C.A.; Wilcox, S.M. (2011). "Assessment of Spatial and Temporal Variability in the U.S. Solar Resource from Radiometric Measurements and Predictions from Models Using Ground-Based or Satellite Data.” Solar Energy (85); pp. 1,068-1,084.

Mesinger, F., et al. (2006). "North American Regional Reanalysis." Bulletin of the American Meteorological Society (87); pp. 343-360.

Sawaqed, N.M.; Zurigat, Y.H.; Al-Hinai, H. (2005). “A Step-by-Step Application of Sandia Method in Developing Typical Meteorological Years for Different Locations." International Journal of Energy Research (29:8); pp. 723-737.

Wilcox, S.; Marion, W. (2008). Users Manual for TMY3 Data Sets. NREL/TP-581-43156. Golden, Colorado: National Renewable Energy Laboratory, April. Accessed November 2013: http://www.nrel.gov/docs/fy08osti/43156.pdf. 


\section{Appendix A: Monthly Spatial Variability}

\subsection{Monthly DNI Spatial Differences for the 3 x 3 Grid}

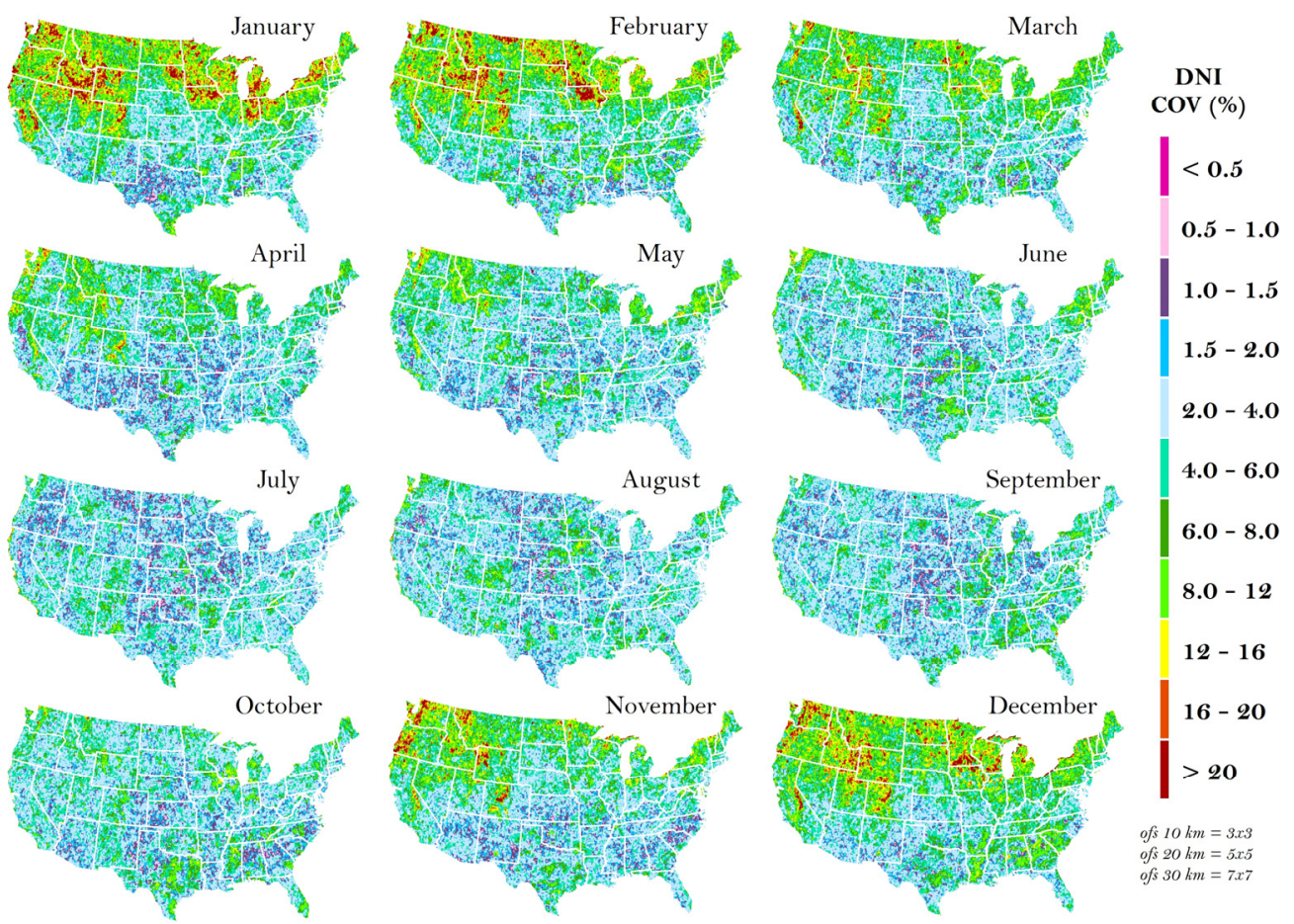

\section{Typical TMY Year - Monthly Spatial COV in a 3x3 Matrix}

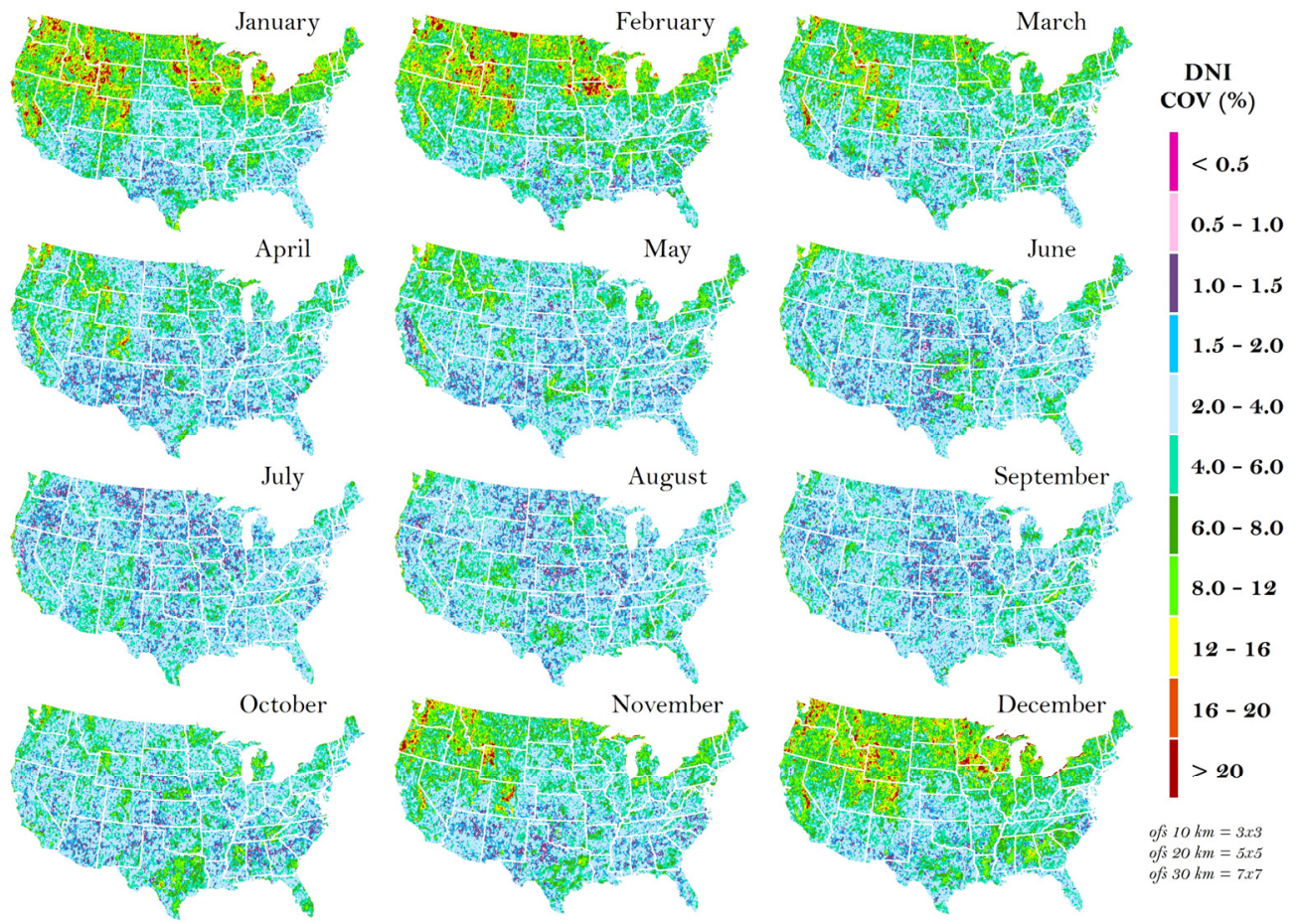

Typical DNI Year - Monthly Spatial COV in a 3x3 Matrix

This report is available at no cost from the National Renewable Energy Laboratory (NREL) at www.nrel.gov/publications. 


\subsection{Monthly DNI Spatial Differences for the 5 x 5 Grid}

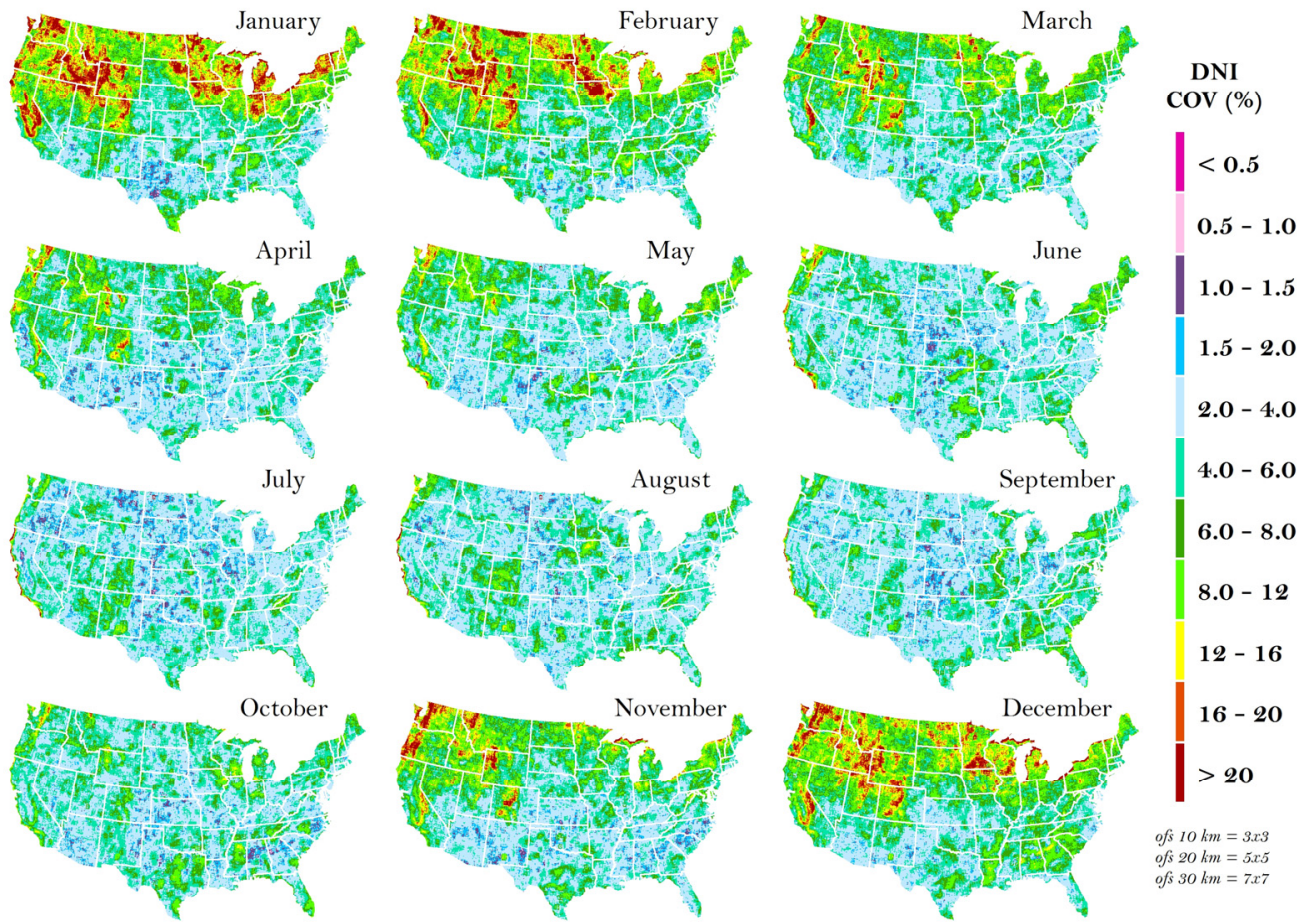

Typical Meteorological Year - Monthly Spatial COV in a 5x5 Matrix

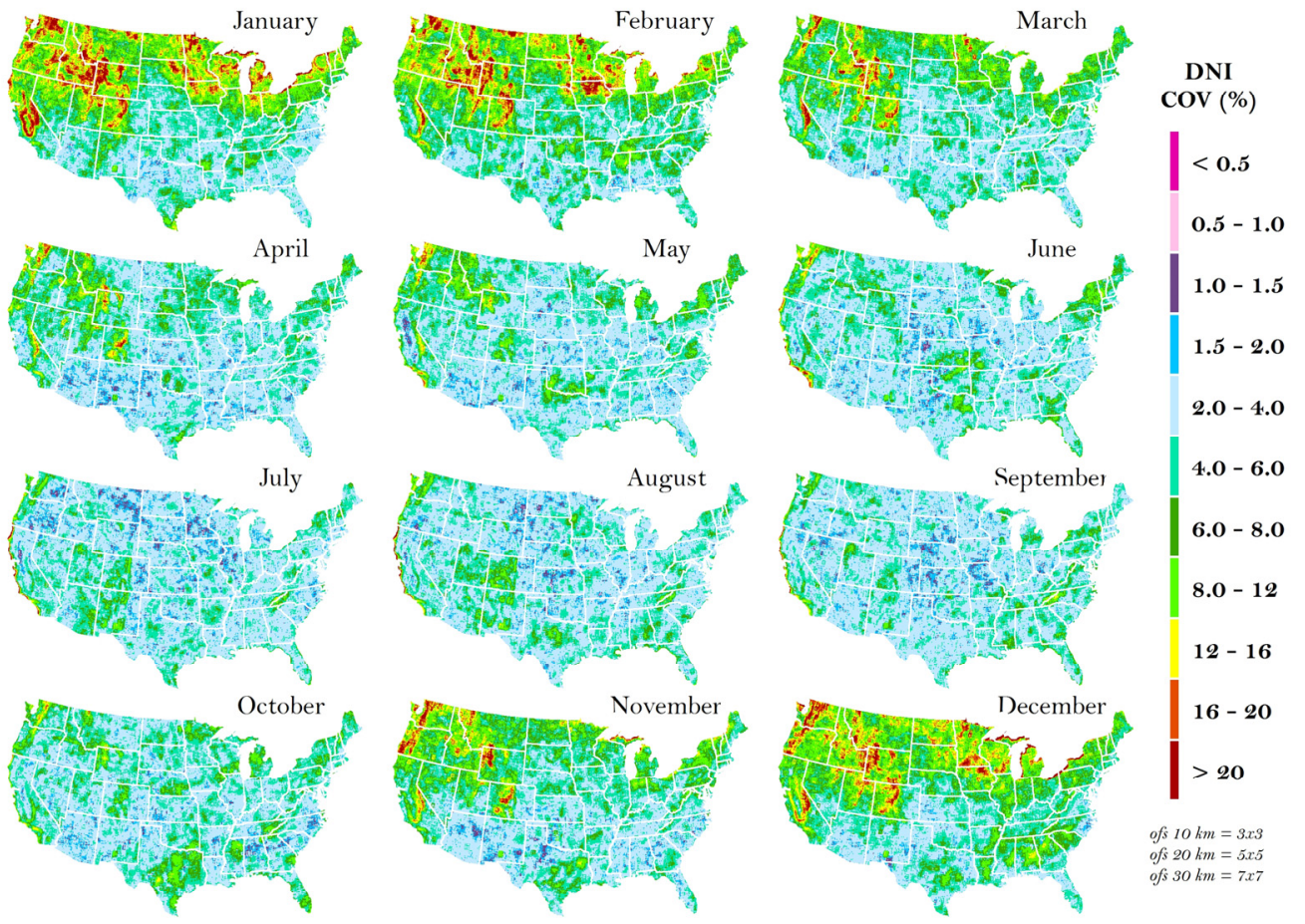

Typical DNI Year - Monthly Spatial COV in a 5x5 Matrix

This report is available at no cost from the National Renewable Energy Laboratory (NREL) at www.nrel.gov/publications. 


\subsection{Monthly DNI Spatial Differences for the $7 \times 7$ Grid}

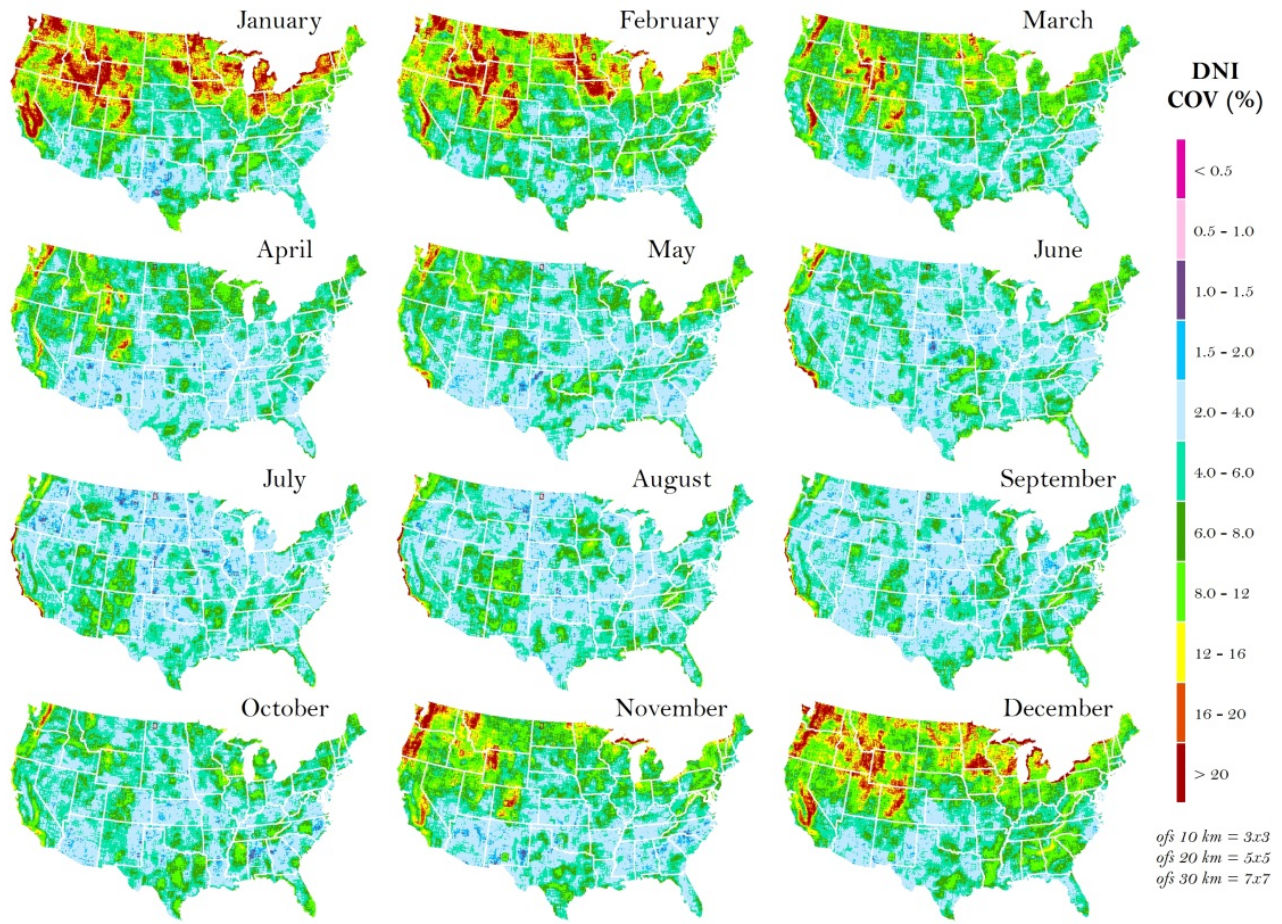

Typical Meteorological Year - Monthly Spatial COV in a 7x7 Matrix

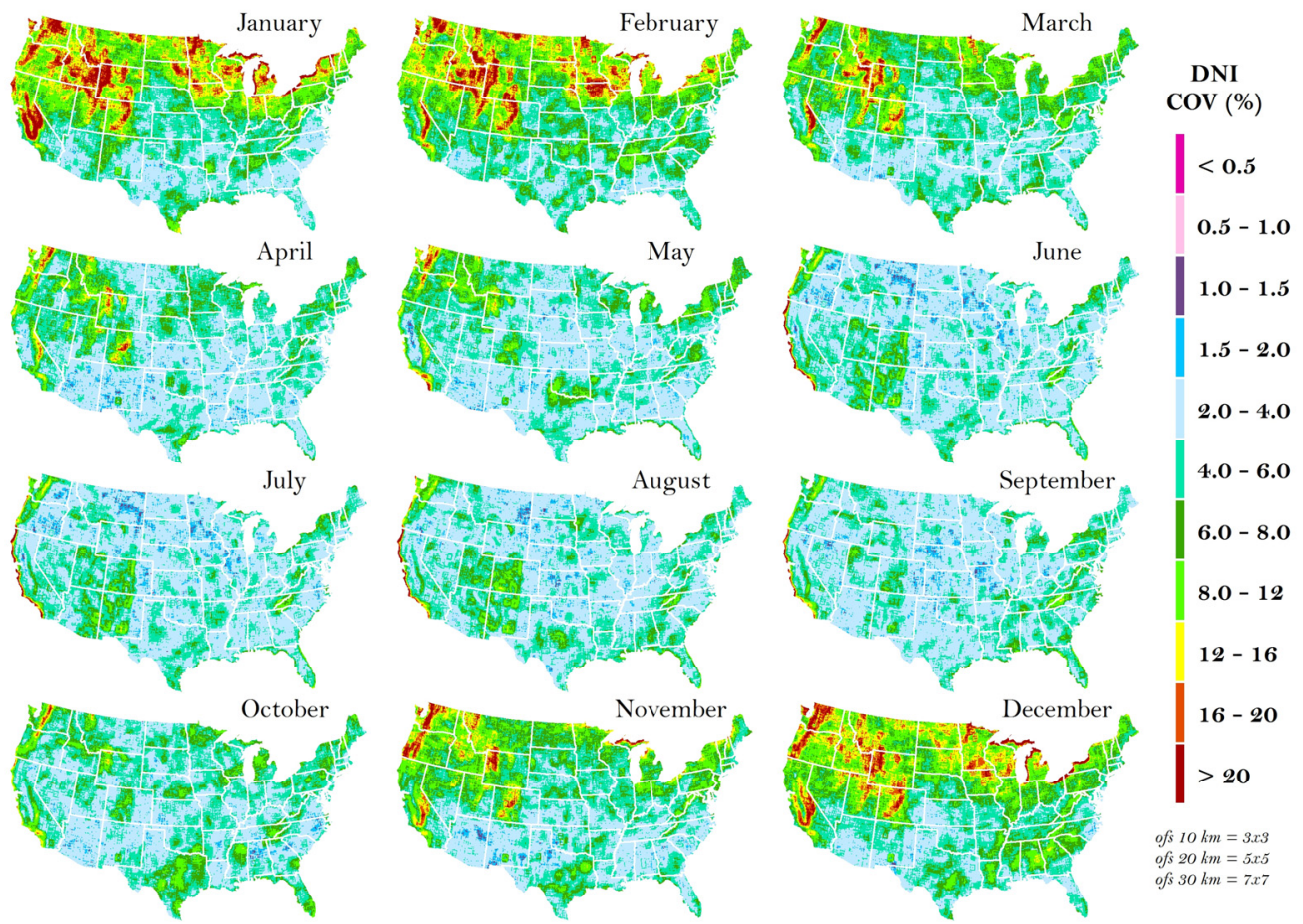

Typical DNI Year - Monthly Spatial COV in a 7x7 Matrix

This report is available at no cost from the National Renewable Energy Laboratory (NREL) at www.nrel.gov/publications. 


\subsection{Monthly GHI Spatial Differences for the 3 x 3 Grid}

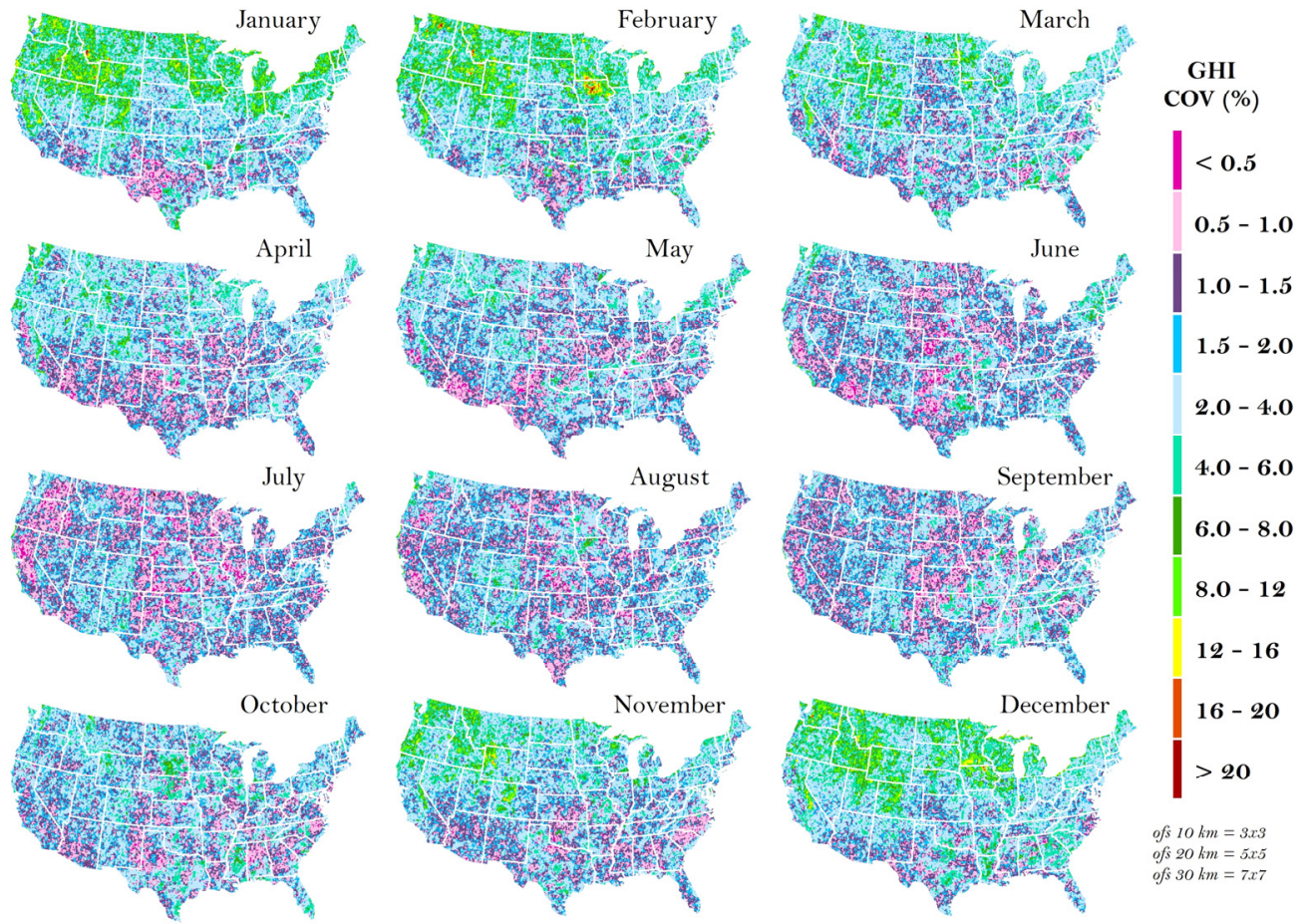

Typical Meteorological Year - Monthly Spatial COV in a 3x3 Matrix

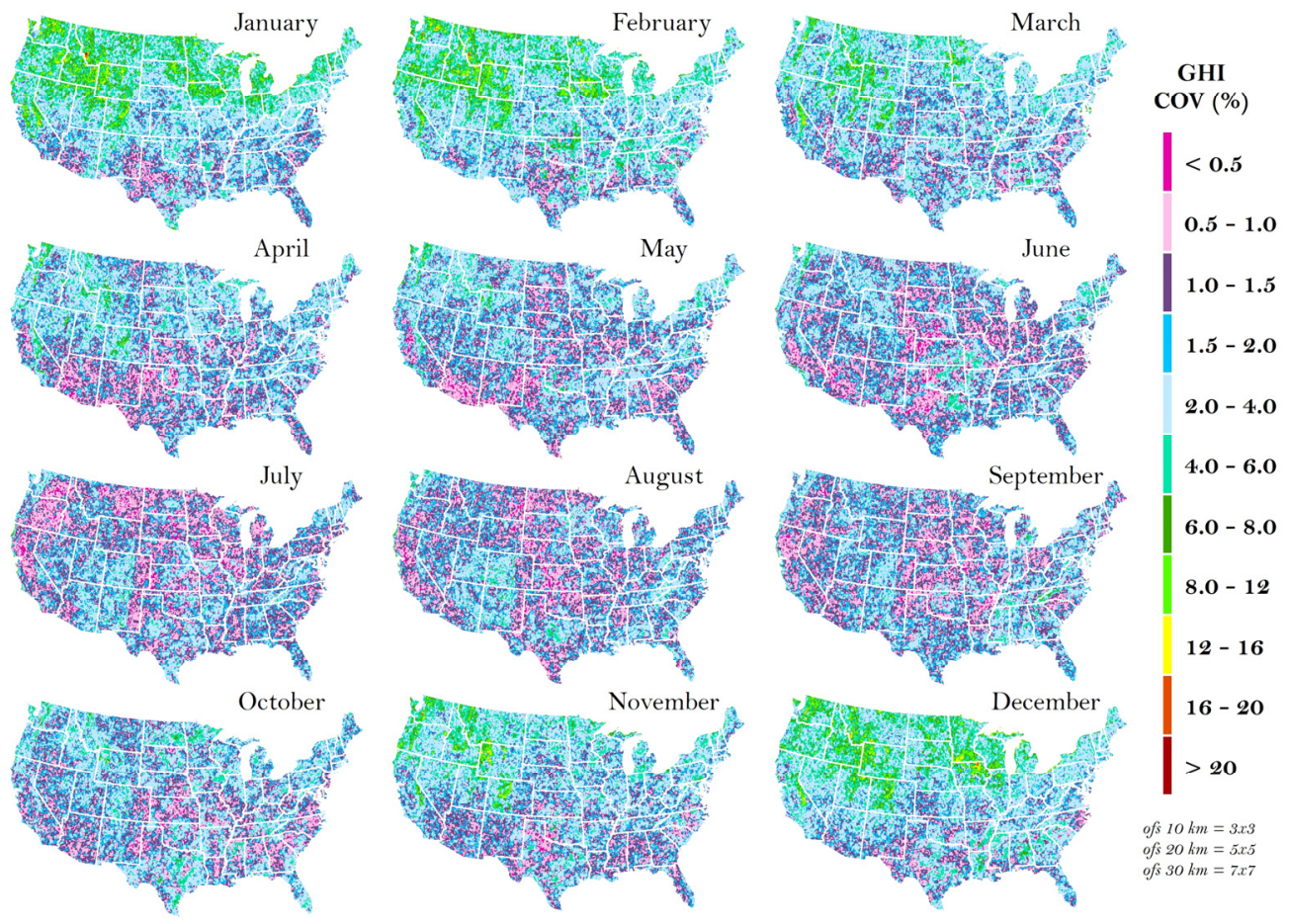

Typical GHI Year - Monthly Spatial COV in a 3x3 Matrix

This report is available at no cost from the National Renewable Energy Laboratory (NREL) at www.nrel.gov/publications. 


\subsection{Monthly GHI Spatial Differences for the 5 x 5 Grid}

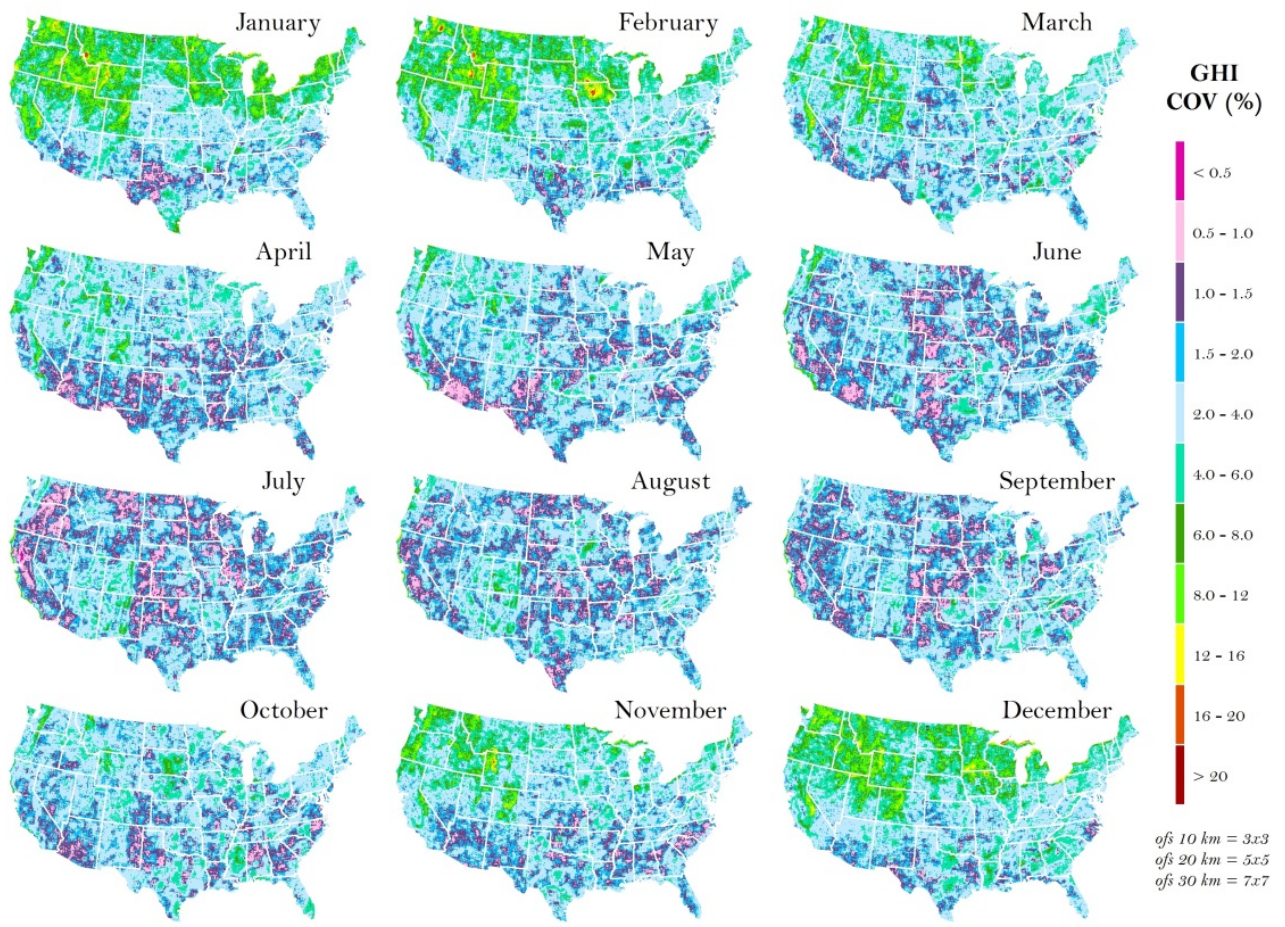

Typical Meteorological Year - Monthly Spatial COV in a 5x5 Matrix

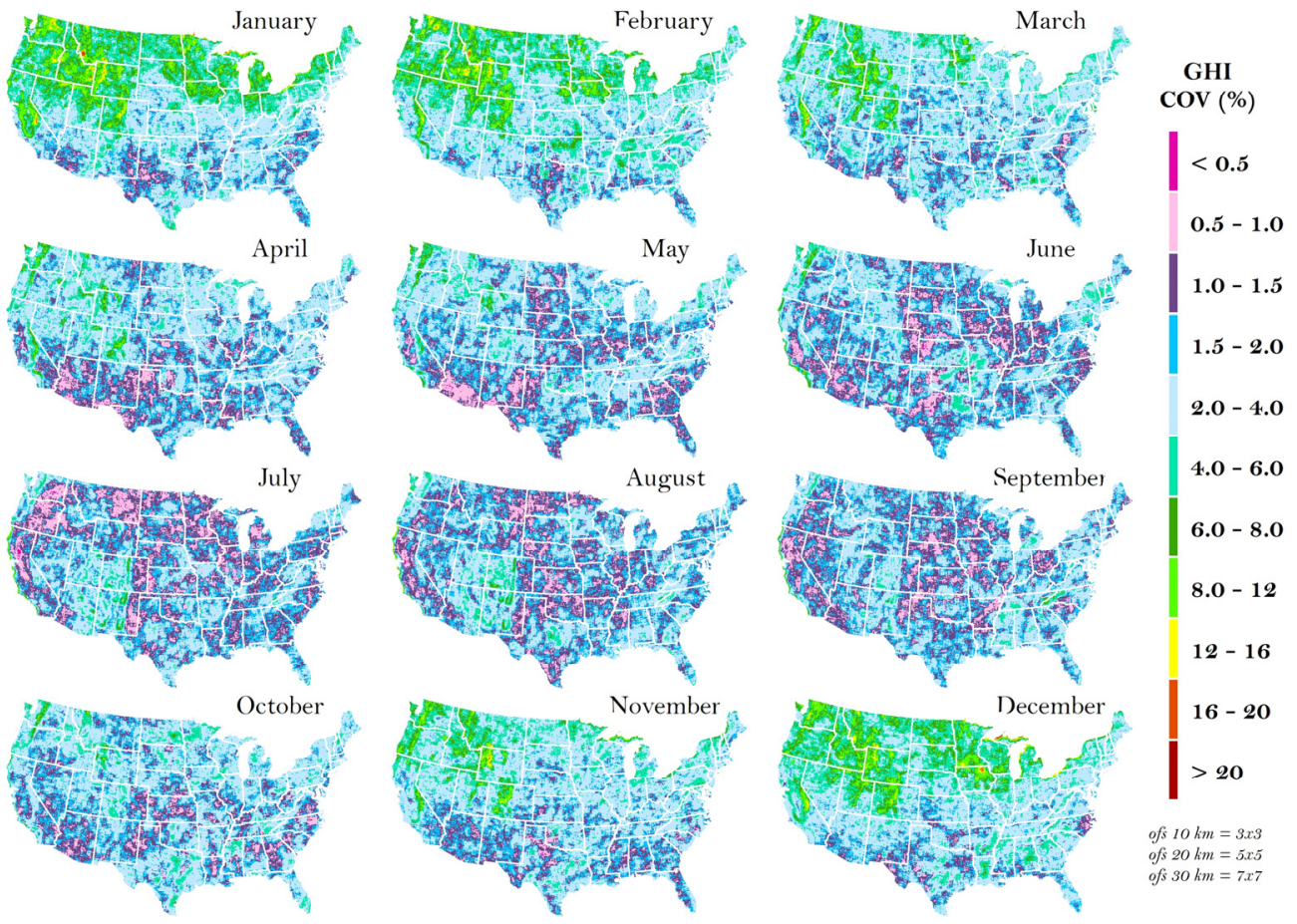

Typical GHI Year - Monthly Spatial COV in a 5x5 Matrix

This report is available at no cost from the National Renewable Energy Laboratory (NREL) at www.nrel.gov/publications. 


\subsection{Monthly GHI Spatial Differences for the 7 x 7 Grid}

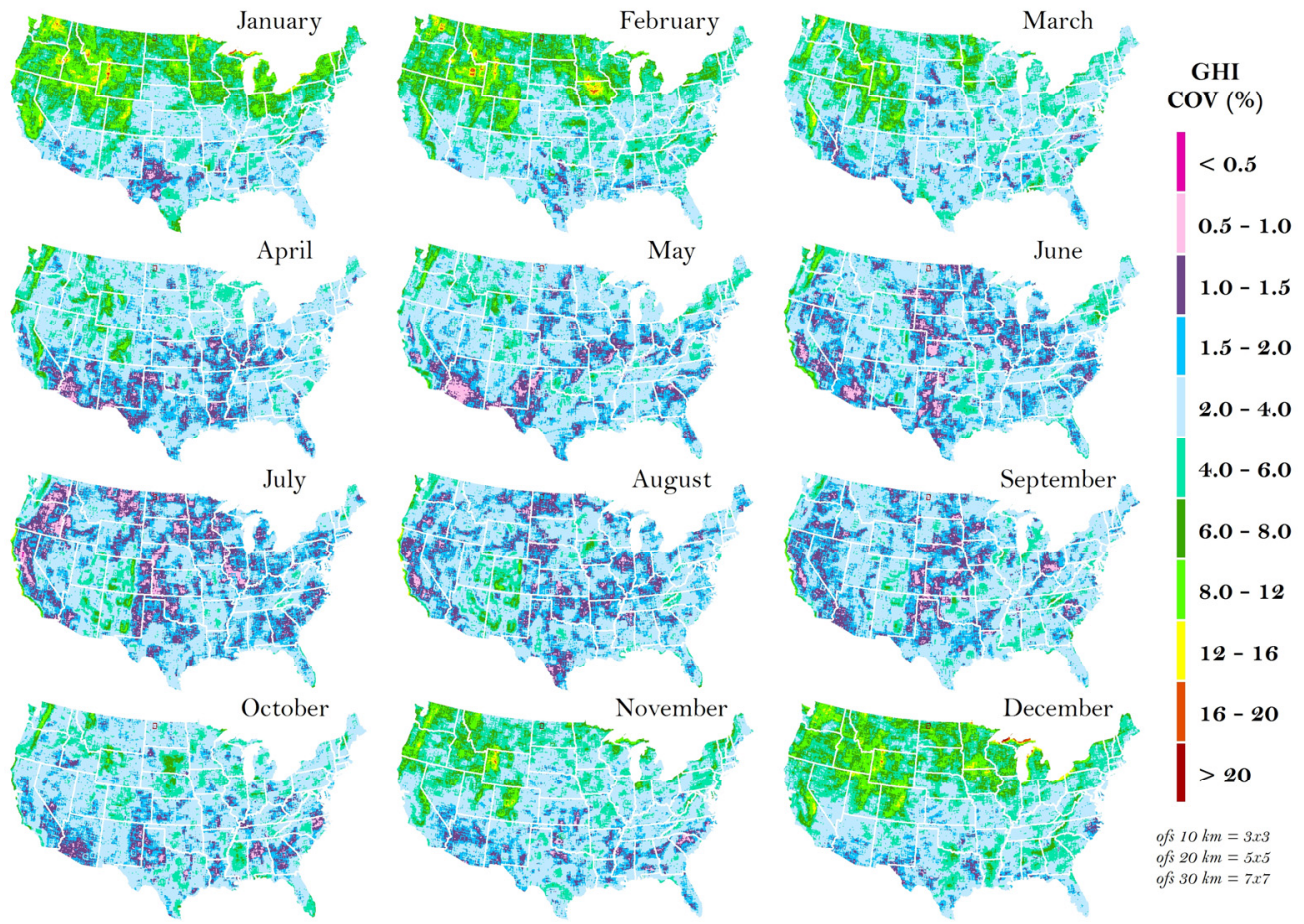

Typical Meteorological Year - Monthly Spatial COV in a 7x7 Matrix

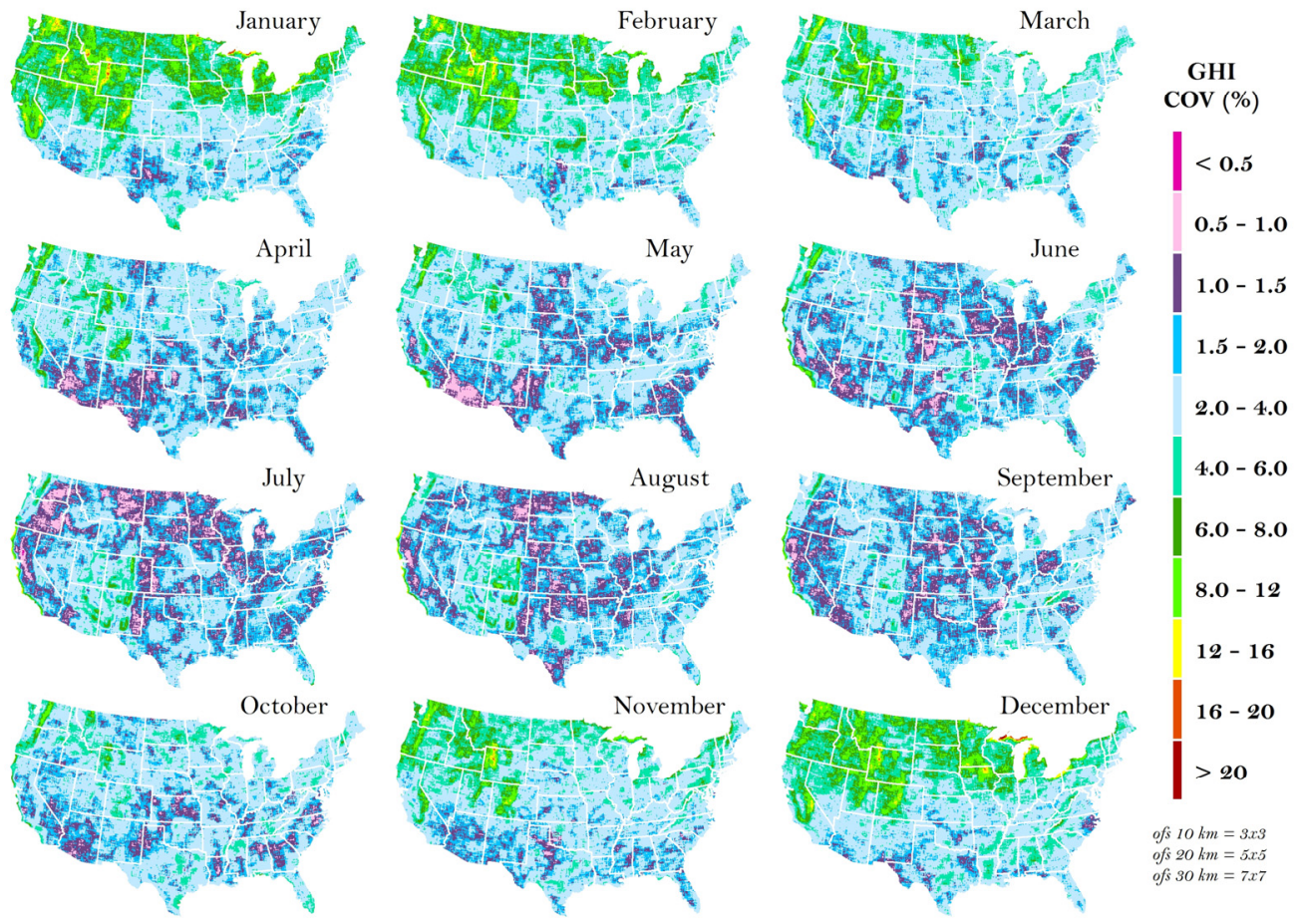

Typical GHI Year - Monthly Spatial COV in a $7 x 7$ Matrix

This report is available at no cost from the National Renewable Energy Laboratory (NREL) at www.nrel.gov/publications. 


\section{Appendix B: Monthly Temporal Variability}

\subsection{Monthly DNI Standard Deviation (\%)}
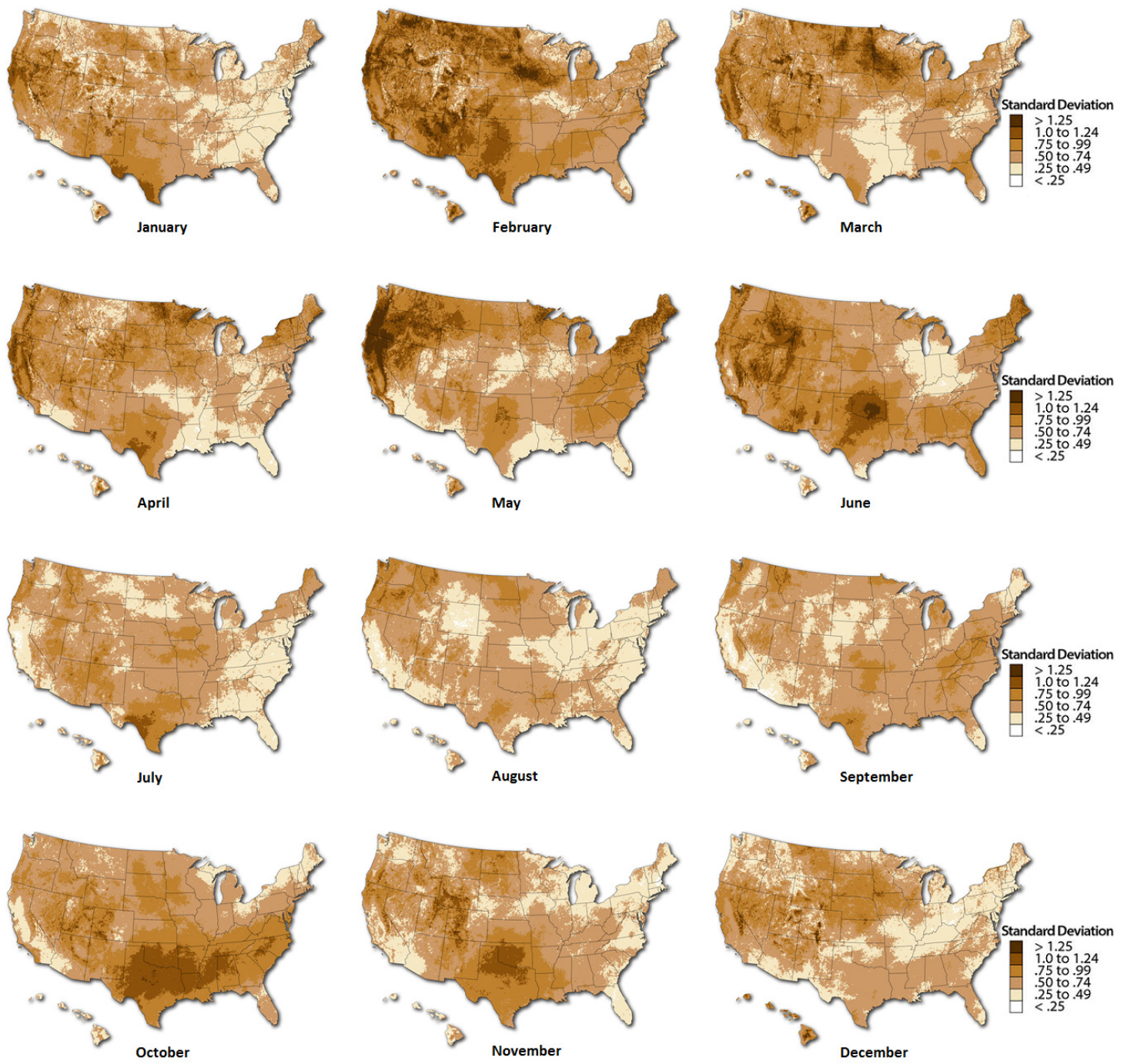

This report is available at no cost from the National Renewable Energy Laboratory (NREL) at www.nrel.gov/publications. 


\subsection{Monthly GHI Standard Deviation (\%)}
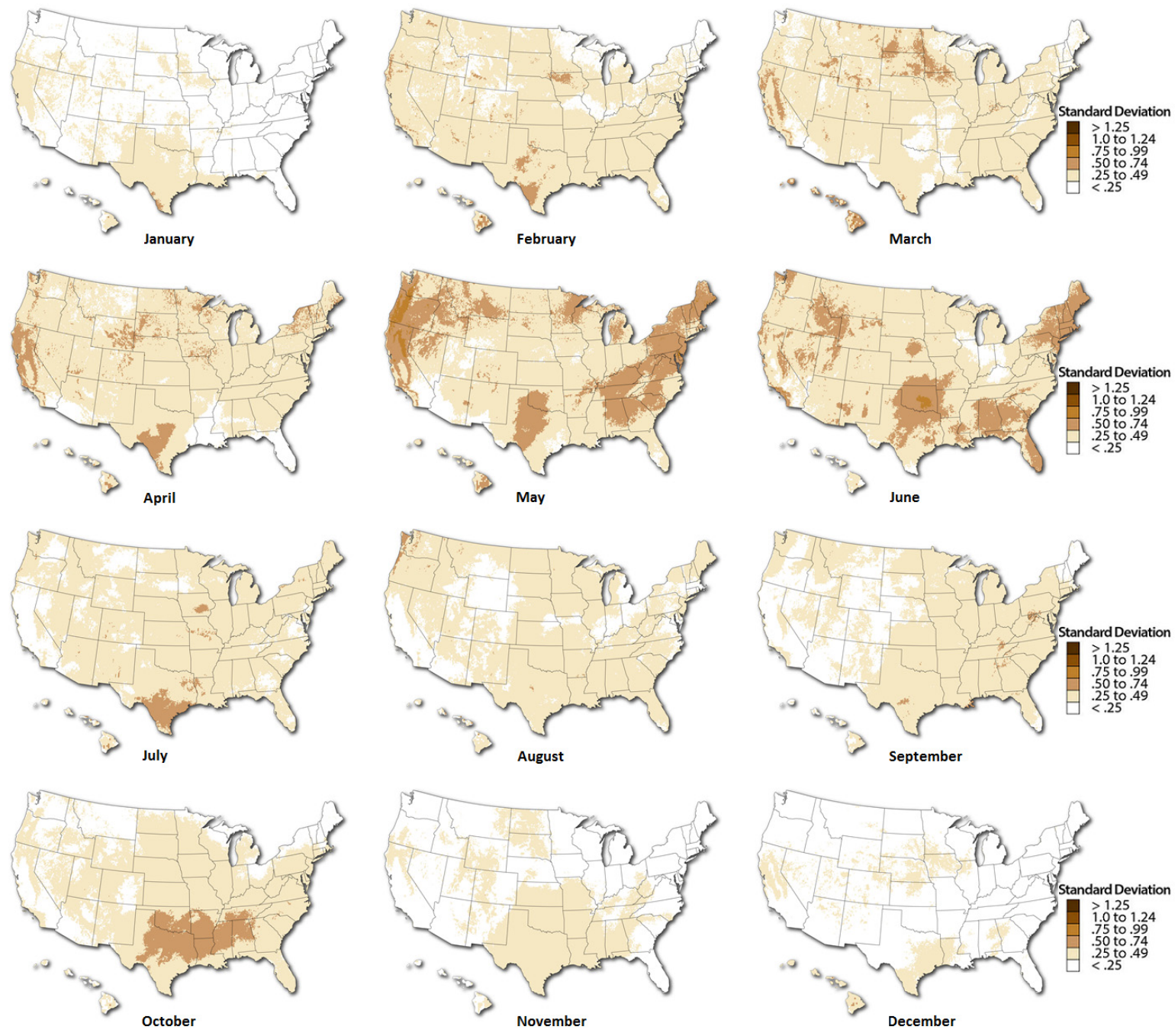

This report is available at no cost from the National Renewable Energy Laboratory (NREL) at www.nrel.gov/publications. 